\title{
Place of cryotherapy, brachytherapy and photodynamic therapy in therapeutic bronchoscopy of lung cancers
}

\author{
J-M. Vergnon*, R.M. Huber ${ }^{\#}$ and K. Moghissi"
}

\section{CONTENTS}

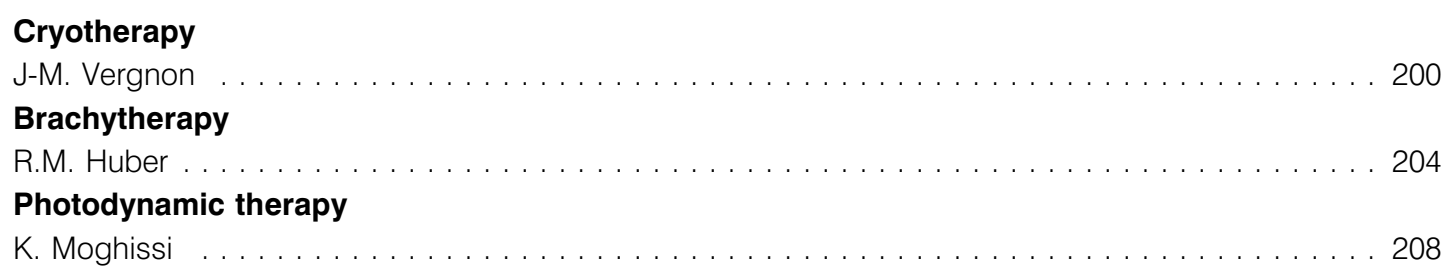

ABSTRACT: Cryotherapy, brachytherapy and photodynamic therapy (PDT) are three different methods proposed in the endoluminal treatment of lung cancers. The current article presents an overview of the specific indications and limits of each technique.

These three methods were first proposed with palliative intent in inoperable patients with centrally located lung cancers. Now, the best indication is a curative intent in early stage lung cancers.

Of the three, cryotherapy is the cheapest method. It induces cell necrosis in a 3-mm radius around the probe, and is suitable for treatment of superficial tumours. However, clinical trials are limited. In contrast, many clinical studies have confirmed the efficacy of PDT in treatment of superficial lung cancers. Brachytherapy can cure more aggressive tumours with deeper invasion into the bronchial wall. Unfortunately, no comparative studies have been published. Each of these methods induces a delayed tumour necrosis, and thus neither is indicated in the treatment of obstructive tumours with acute dyspnoea. In many situations, these methods should be complementary, particularly cryotherapy and brachytherapy or PDT and brachytherapy.

The combination of these endoscopic methods with chemotherapy should be widely tested to promote the adjuvant role of the endoscopic methods in the treatment of lung cancers.

KEYWORDS: Brachytherapy, bronchoscopy, cryotherapy, lung cancer, photodynamic therapy

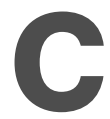
ryotherapy, brachytherapy and photodynamic therapy (PDT) are three different endobronchial techniques with specific indications. Each of them induces a delayed response, and thus is not indicated in the treatment of obstructive tumours with acute dyspnoea. The aim of the present paper is to describe each method, its indications and limits, enabling selection of the best treatment option for each situation encountered.

\section{CRYOTHERAPY}

Compared with other methods used to treat endobronchial tumours, cryotherapy is unique. This method offers delayed tumour destruction similar to PDT at a cost cheaper than electrocautery, and with the safety of not inducing collagen damage or bronchial wall perforation. Cryotherapy is therefore used to treat infiltrative tumours, including in situ cancers. The specific action of cryotherapy on apoptosis and on poorly

Previous articles in this series: No. 1: Bolliger CT, Sutedja TG, Strausz $\mathrm{J}$ and Freitag L. Therapeutic bronchoscopy with immediate effect: laser, electrocautery, argon plasma coagulation and stents. Eur Respir J 2006; 27: 1258-1271. 
vascularised tumour cells allows the use of cryotherapy in combination with irradiation or chemotherapy.

\section{Background}

The analgesic and anti-inflammatory properties of cold have been known for centuries. Larrey used these properties in 1812 to achieve haemostatic and analgesic effects in surgical amputations during the Russian campaign. In 1851, ARNOTT [1] made reference to the role played by low temperatures in destroying tumours. In 1959, the first clinical application on brain tumours using closed-circuit probes was published [2] Later on, cryotherapy was widely used in the treatment of a variety of tumours. In 1968, GAGE [3] reported the first endoscopic treatment on a bronchial tumour in the USA. Both articles [2,3] received little attention, despite the fact that there were several publications from 1962 to 1983 [4-8] dealing with the same subject. Laser therapy was preferred. Bronchial cryotherapy was renewed in France in 1986, following studies by HOMASSON [9]. Since then, $>1,500$ patients have been treated in France and the UK [10-14]. Based on this clinical experience, the techniques and limits of cryotherapy were defined on both bulky tumours and in early stage lesions. The combination of cryotherapy with irradiation or chemotherapy was then tested in humans and produced encouraging results $[15,16]$. Since 1996, interest in cryotherapy has grown in the USA with the introduction of flexible probes [17]. Currently, the cytotoxic mechanisms of cryotherapy and the potential for synergistic action with chemotherapy are being investigated through in vivo studies [18].

\section{Principles}

Cryotherapy is a unique method of destruction based on the cytotoxic effects of cold on living tissue. The application of a low-temperature probe on a tissue first induces an immediate adherence between the probe and the tissue and then the

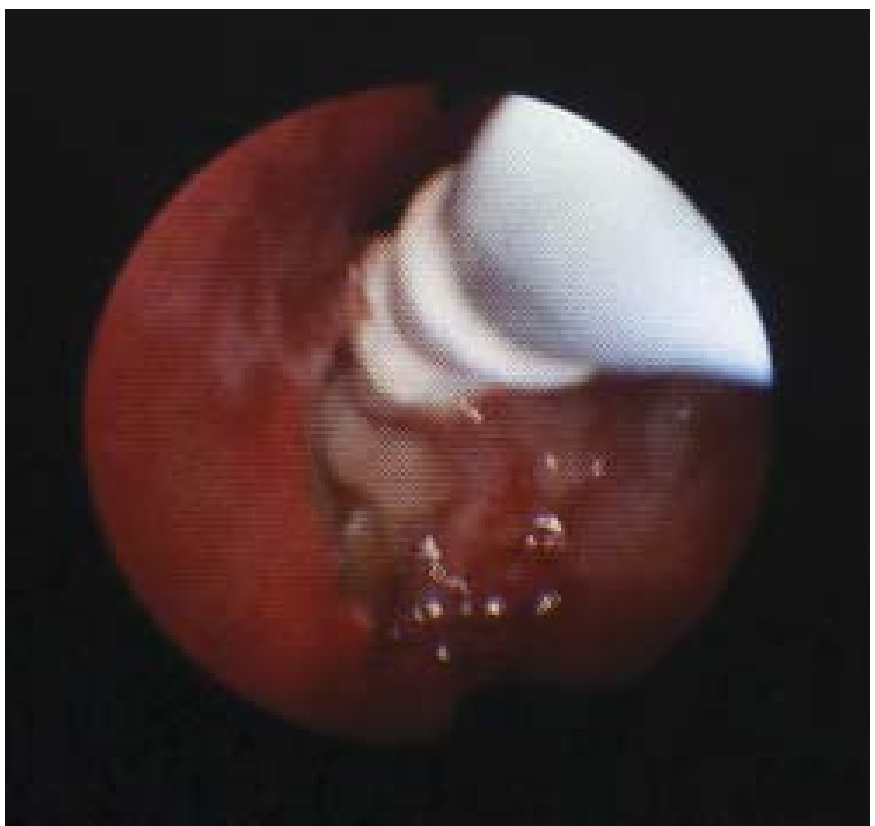

FIGURE 1. Flexible cryoprobe used to treat a tumoral obstruction in the right upper lobe appearance of intra- and extracellular ice crystals [19-23]. These crystals damage intracellular organelles, especially mitochondria. The formation of pure extracellular ice crystals causes additional ion and water movements resulting in cellular dehydration. In order to obtain a maximum lethal effect, it is necessary to have large ice crystals, especially at the intra-cellular level. This effect is achieved by rapid cooling of the tissue followed by slow thawing [10]. This principle is the opposite of cryopreservation. In tumour tissue, thawing occurs by vascularisation, where cold waves move radially around the point of application of the cryoprobe. At each point, cytodestruction varies according to the speed of freezing and thawing. Cytotoxicity diminishes with distance from the centre of application, as well as when near the permeable vessels [18, 19]. This physical and cellular phenomenon is coupled with a vascular effect: an initial vasoconstriction occurs, which is followed by a vasodilatation. A complete vascular thrombosis appears 6-12 $\mathrm{h}$ later, thus completing the physical cytodestruction by induction of local infarction [19-23].

In the more peripheral area, the destruction is inhomogeneous, and the vessels that remain permeable protect some perivascular cells from destruction [21]. It has been demonstrated that apoptosis is the main phenomenon in this zone [18].

The area of destruction through cryotherapy has a diameter of $\sim 1 \mathrm{~cm}$ when a $3-\mathrm{mm}$ diameter probe is used [9]. When in lateral contact with a bronchial wall, cytotoxicity can be considered complete to a depth of $3 \mathrm{~mm}$. Nonhaemorrhagic necrosis of the tissue occurs 8-15 days following the procedure. Collagen, cartilage or poorly vascularised tissues are very cryo-resistant [11].

These data explain the essential characteristics of cryotherapy: a spherical pure cytotoxic action leading to late tissue necrosis and an important late haemostatic effect. The high cold resistance of the supporting bronchial structure explains the safety of this method. There is neither risk of bronchial perforation nor scarring with residual fibrous stenosis. The cold wave kills poorly vascularised cells and spares perivascular cells. Thus, the vascular density increases in the residual tumour. The current author also observed an enhancement of vascular endothelial growth factor expression in the residual tumour cells. These results support the principles of cryoradiotherapy [16] and cryo-chemotherapy studies [15].

\section{Materials and methods}

\section{Devices}

Two types of probes are available: liquid nitrogen probes, which are very powerful but awkward to use, and nitrous oxide $\left(\mathrm{N}_{2} \mathrm{O}\right)$-driven cryoprobes (figs 1 and 2). Cooling is due to the Joule-Thompson principle, cooling of a gas by sudden expansion from a high to a low pressure zone. Flexible cryoprobes of $2-3 \mathrm{~mm}$ in diameter are available and can be used through a flexible fibreoptic bronchoscope [18]. Recently, reinforced cryoprobes were manufactured in order to extract pieces of tumour after the adherence phase [24]. Personally, the present author prefers and recommends rigid cryoprobes used through a rigid bronchoscope. The rigid cryoprobe is more powerful than the flexible probe. A footpad or a trigger on the handle allows immediate and active thawing of the probe after cooling. This contrasts with flexible probes where thawing is 


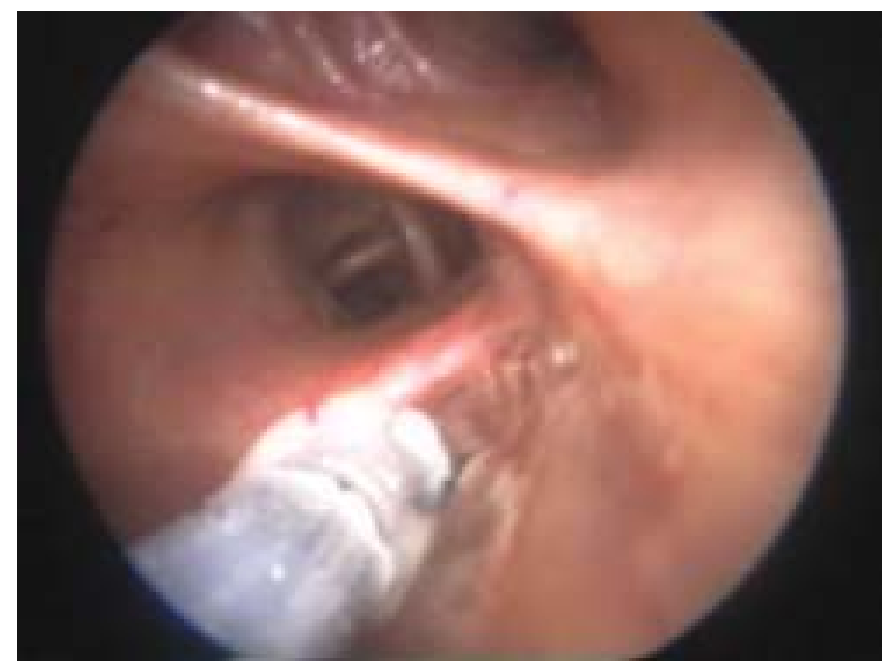

FIGURE 2. Rigid-probe cryotherapy of an early stage lung cancer located on a right lower lobe carena.

passive. Thus, with flexible probes, each cycle of freezing and thawing lasts double the amount of time compared with a rigid probe cycle. The rigid probe used by the present author is $60 \mathrm{~cm}$ long and $3 \mathrm{~mm}$ in diameter. Only the 1-cm tip of the probe causes freezing of tissues; the remainder of the probe is insulated. The external temperature obtained at the tip of the probe is $<-40^{\circ} \mathrm{C}$ and is obtained in $1-2 \mathrm{~s}[22,23]$. The probe is connected to a cylinder of purified $\mathrm{N}_{2} \mathrm{O}$ at a pressure of 50 bar. The main equipment is supplied by ERBE (Tübingen, Germany), but other equipment is supplied by DATE (La Motte d'Aveillans, France) or Spembly Medical Ltd (Andover, UK).

\section{Methods}

In St. Etienne University Hospital (St. Etienne, France), the patients are admitted to hospital the day before the treatment and discharged the following day. Procedures are performed by introducing the rigid cryoprobe into a rigid bronchoscope. High oxygen concentration can be delivered without any restriction during cryotherapy. Local anaesthesia alone is used when cryotherapy is performed through a flexible bronchoscope. It is notable that cryotherapy is not a painful procedure. Once the lesion to be removed is found, the tip of the cryoprobe can be pushed into the protruding exophytic tumour or applied laterally onto infiltrative tumours and in situ carcinomas. Generally, three cycles of freezing and thawing are performed at each location. Each freezing period is short, at $\sim 20 \mathrm{~s}$. When an impedance meter is used, the freezing phase is stopped once a plateau of impedance is obtained. After three cycles, the tip of the probe is moved to touch an adjacent part of the tumour. Although the obtained ice-ball is $\sim 10 \mathrm{~mm}$ in diameter, the adjacent impact of the probe must be $\sim 5 \mathrm{~mm}$ from the first impact to make the iceball overlap. It is important to cover the entire surface of the tumour (30 or more cycles are often necessary). In cases of early stage lung cancers, the limits of the lesion should be delineated by autofluorescence endoscopy. Without this technique, a margin of $5 \mathrm{~mm}$ around the visible limits of the tumour should be treated. In cases of tumour located on a carina, the two sides of the carina and the crest should be treated. At the end of the procedure, the tumour appears undamaged. Indeed, cryothrombosis is delayed for several hours. In the present author's opinion, it is dangerous to mechanically remove any part of the tumour at this stage. For this reason, cryotherapy is not recommended when patients present with an acute dyspnoea. Even in large tumour treatment, the duration of a cryotherapy session using rigid cryoprobe (with active "immediate" thawing) remains short, between 20 and $45 \mathrm{~min}$.

Between 8 and 10 days after cryotherapy, the necrotic sloughed tissue is eliminated by expectoration or removed by forceps during a follow-up fibreoptic bronchoscopy. Generally, when cryotherapy is used alone, a second session should be planned to eliminate the residual tumour.

\section{Indications and complications of cryotherapy}

Indications

The effects of cryotherapy are delayed. This technique, therefore, is not indicated to achieve immediate debulking of an obstructive tumour. In these cases, the tumour will first be cored out mechanically with the tip of the rigid bronchoscope after coagulation (if necessary) with laser beam or electrocautery. After this first step, and in the same session, cryotherapy can be applied on the remaining infiltrative part of the tumour (fig. 3).

Cryotherapy is very efficient on cellular and well-vascularised tumours such as bronchial carcinomas, carcinoids (fig. 4a and b), adenoid cystic carcinomas or granulomas. In the present author's experience, 18 cases of endoluminal typical carcinoids have been treated and cured with the combination of laserassisted mechanical resection followed by cryotherapy. The median follow-up was 30 months. In lung cancers, the effectiveness of cryotherapy reaches $\sim 75 \%$, regardless of the cellular type or the endoluminal aspect [12, 14, 19, 23]. Due to the deep $(3 \mathrm{~mm})$ and safe cytotoxic action against tumour cells in the bronchial wall, this method can be used to safely treat in situ or micro-invasive carcinomas (fig. 2). The results of a multicentre French study of 35 cases has been reported [25]; an $80 \%$ complete cure with a mean follow-up of 32 months was observed. The remarkable action of cryotherapy on tumour vascularisation also explains its effectiveness on haemoptysis. The control ranged $60-86 \%[12,19,23]$.

The present author believes that this method of cryotherapy, as well as PDT, could now be dedicated to the treatment of stalks of resected tumours or early stage lung cancers.
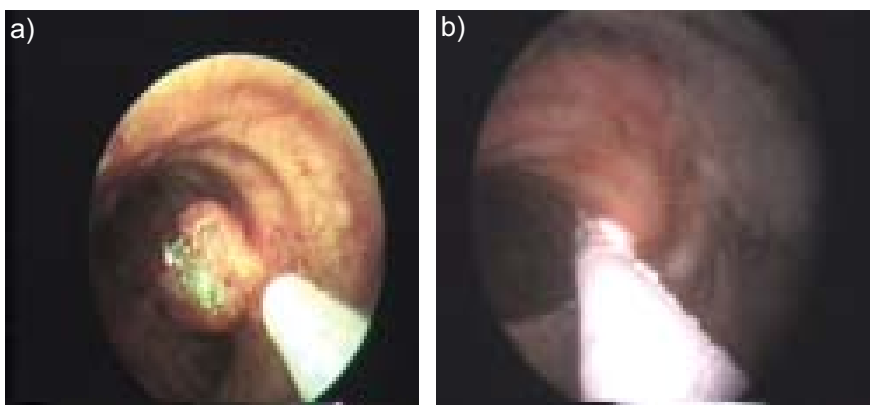

FIGURE 3. Metastatic renal tumour in the trachea treated with a) laser-assisted resection and then b) cryotherapy, applied on the residual stalk. 

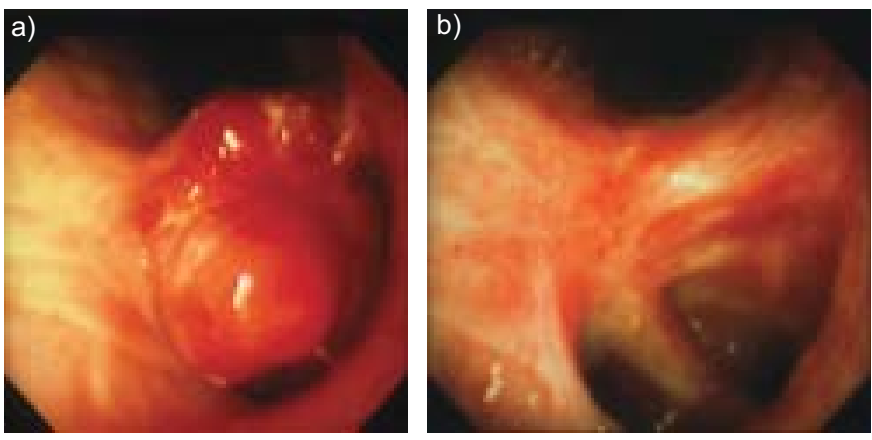

FIGURE 4. Typical carcinoid of the right upper lobe treated with cryotherapy alone: aspect a) before and b) 2 weeks after the treatment, showing a perfect result with no stricture. (Supplied courtesy of R. Jean-François, Montreal University Hospital, Montreal, Canada.)

Collagen tissue, poorly cellular tumours and fibrous scars are not so cryosensitive, thus cryotherapy alone is not indicated in benign strictures of the trachea or bronchi caused by fibromas, lipomas or post-intubation stenosis. Cryotherapy is not indicated in external compression of the bronchial tree. Cryotherapy is, however, useful to remove many foreign bodies from the airways (fig. 5). Efficient cryo-adherence is observed with porous structures, such as pills, food, blood clots or peanuts. In contrast, cryo-adherence is less efficient with bones, metal or teeth.

\section{Complications}

Cryotherapy is a very safe method without risk of perforation or residual stenosis even after circumferential treatment. This contrasts with electrocautery which, even in soft mode, has a risk of perforation or residual stenosis. Two side-effects of cryotherapy have been observed. 1) A transient fever immediately following cryotherapy. Interestingly, this fever can be prevented by corticosteroid administration given during the procedure. The present author speculates that this fever could be associated with the cell necrosis and a release of tumour necrosis factor. 2) Airway-sloughing material elimination after cryotherapy remains a problem. A similar situation is observed with PDT. The sloughed tissue is often abundant, protruding into and even obstructing the airway lumen. It can induce cough and dyspnoea. A bronchial toilet with a flexible fibreoptic bronchoscope is recommended 8-10 days after cryotherapy.

\section{Therapeutic associations}

Cryotherapy may be of benefit in patients requiring chemotherapy or irradiation therapy, but this hypothesis needs to be proven. Preliminary reports both in animals and humans have shown that pre-treatment with cryotherapy could enhance the concentration of the chemotherapy agent into the tumour $[15,26]$. The benefit of combining cryotherapy with chemotherapy to enhance the induction of cell death either by necrosis or by apoptosis has also been found in a mouse model [18] (fig. 6). With irradiation, a prospective pilot study has been conducted [16], suggesting that the cryotherapy irradiation combination induces a very effective endoluminal control of the tumour associated with an increased survival. This result was confirmed by another study conducted by MAIWAND and HOMASSON [12]. The same results were observed in mice

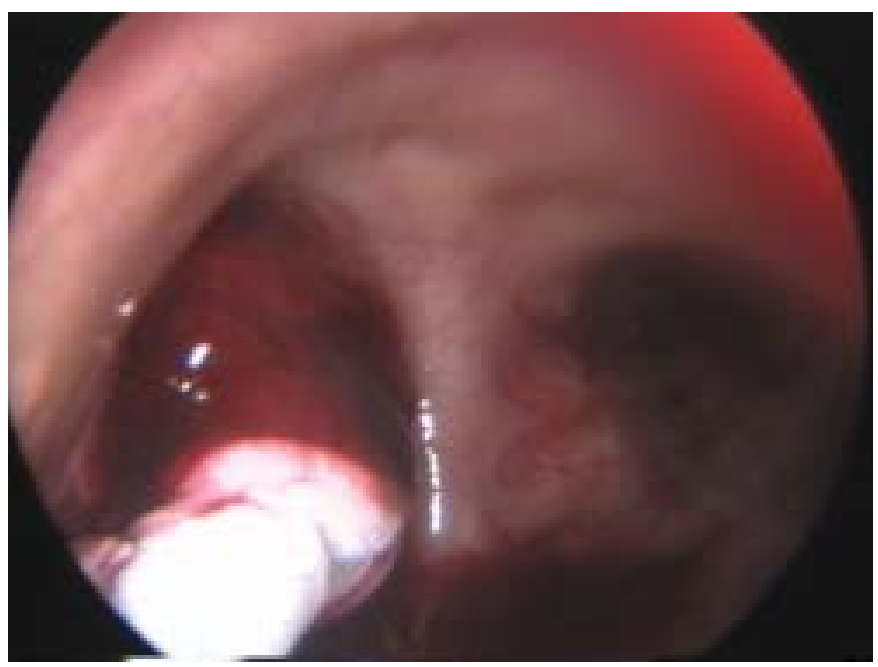

FIGURE 5. Removal of a clot located in the left main stem bronchus with a rigid cryoprobe.

(fig. 7). Unfortunately, these preliminary studies have not yet been followed by larger randomised prospective protocols.

\section{Conclusion}

In 2006, compared with other endobronchial treatments, the role of cryotherapy was still limited. It is the safest and cheapest method but less versatile than electrocautery. It is an excellent method with which to treat early stage lung cancers, but experience is limited and should be confirmed by prospective randomised studies. In lung cancer, results of the combination between cryotherapy and chemotherapy or irradiation are very encouraging but require large prospective human studies.

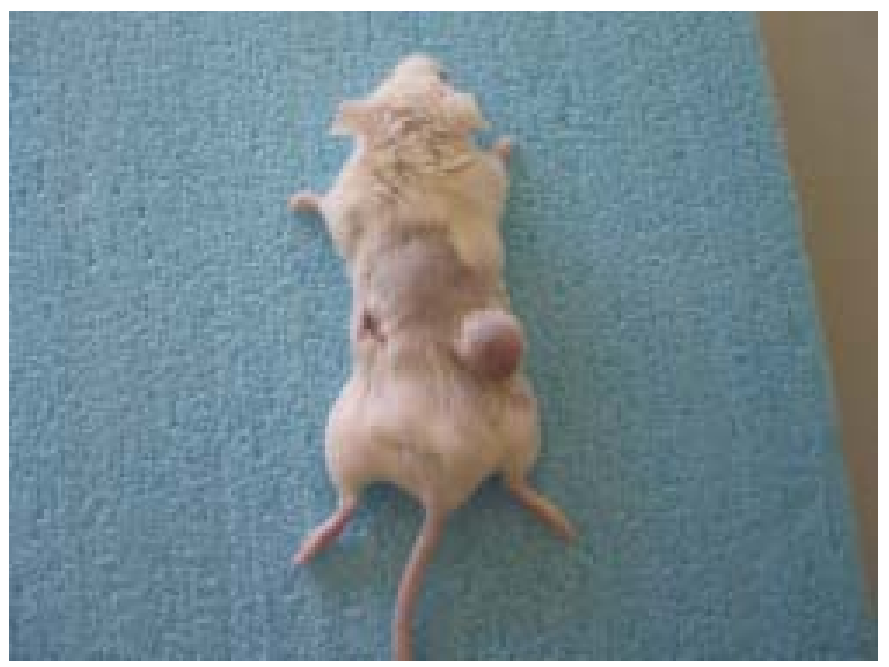

FIGURE 6. Two human lung adenocarcinoma were xenografted on the back of the SKID mouse as shown. The initial size of the two tumours was similar. The aspect of the tumours shown is 2 weeks after a treatment with i.v. vinorelbine (Navelbine ${ }_{\circledR}$; Pierre Fabre Laboratories, Gaillac, France). Only the left tumour was treated before chemotherapy with three cycles of cryotherapy. 


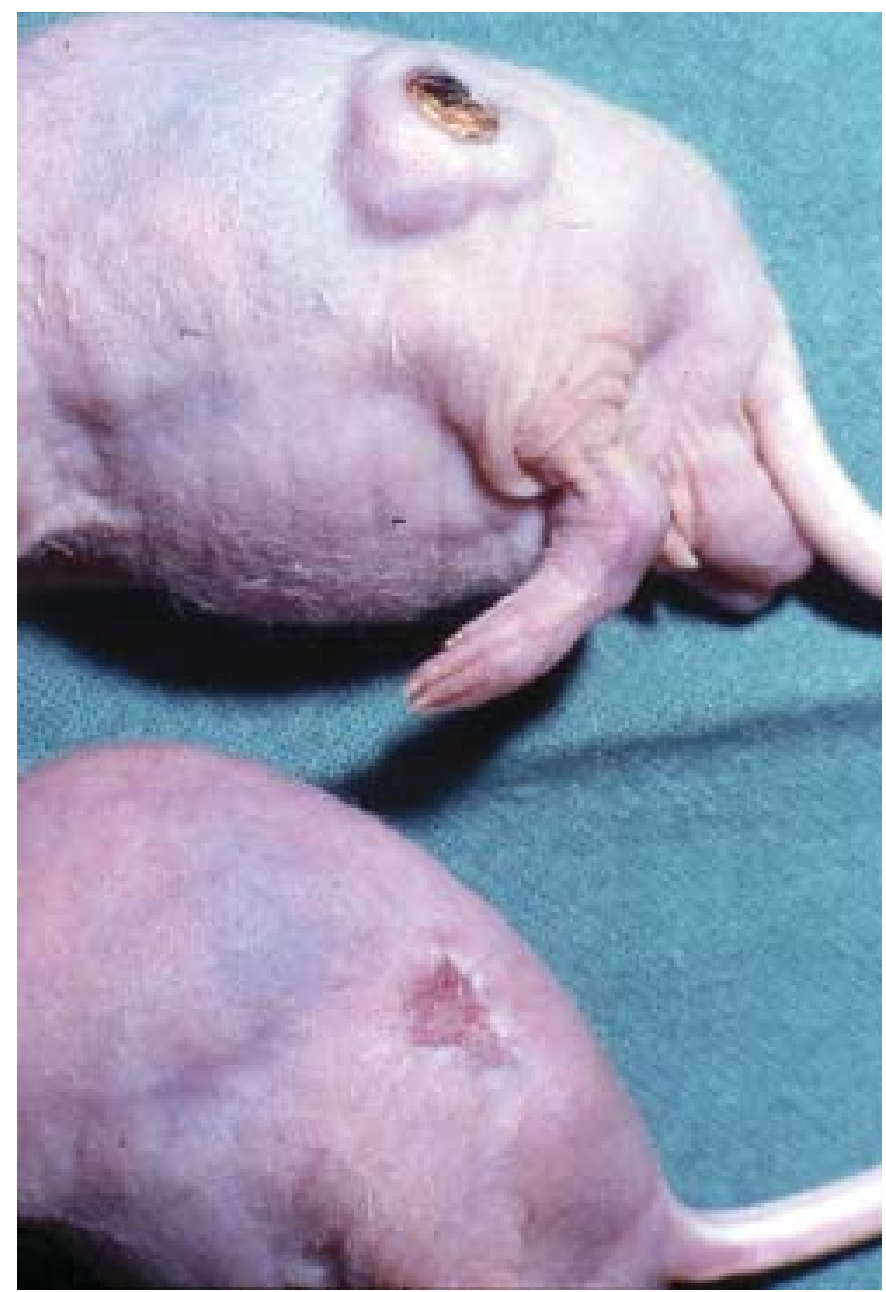

FIGURE 7. Cryotherapy followed by irradiation of human small cell lung cancer xenografted on the back of a "nude" mouse. The mouse at the top underwent irradiation alone. The mouse at the bottom underwent cryotherapy followed by irradiation.

\section{BRACHYTHERAPY \\ Introduction}

For each specific endo- or paraluminal tumour of the tracheobronchial tree, different methods of endobronchial intervention are available. These interventions should be quick, effective, suitable for the patient and the staff, and carry a low risk of complications, especially in the mostly palliative setting. One of these methods is endoluminal brachytherapy. Brachytherapy (brachys (Greek) meaning short) refers to the placement of a radioactive source (usually iridium-192 high dose rate (HDR)) within or near to an endobronchial/parabronchial malignancy to deliver local irradiation. The radioactive source can be implanted directly into the tumour, placed in the tumour bed after surgical resection or applied via the endoluminal endoscopic route. Endoscopic brachytherapy with a HDR system has the advantage of being a minimally invasive procedure, which can be performed on an outpatient basis. Also, it is suitable for patients with a poorer performance status. Furthermore, the equipment is not very expensive. The disadvantage is the time gap between intervention and the macroscopic effects on the tumour. Acute side-effects are very rare and are related to bronchoscopy itself; late effects may be bleeding, the formation of fistulas, radiation bronchitis and consecutive airway stenosis. It may be curative in very early superficial cancers. HDR brachytherapy can also be used for nonmalignant tracheal and bronchial obstruction. Brachytherapy can be combined with all other treatment modalities used in thoracic malignancies. The effect is not limited to the tumour in the lumen and is long lasting. Due to its small radiation volume and the rapid decline of the radiation dose, it is also indicated to palliate symptoms, such as cough, haemoptysis and dyspnoea, in patients who have already received their maximal dose of external beam radiotherapy (EBRT).

\section{Background}

Amongst the currently available interventional bronchoscopic procedures, endobronchial brachytherapy is one of the oldest techniques. The first successful endobronchial implantation of radium capsules (using the ideas from gynaecological implants) was documented as early as 1922 , and further reports also on interstitial therapy have followed [27, 28]. In the 1960 s, cobalt-60 seeds were most frequently used as the radiation source. Both radium and cobalt implants deliver the dose with a relatively low dose rate and therefore require a long treatment time, up to days, which is not suitable for application in the airways. Also, rigid bronchoscopy and general anaesthesia are necessary.

By using brachytherapy, it is possible to deliver a maximum dose to the tumour with a minimum dose to the surrounding normal tissue. However, one of the major drawbacks of this method was found to be the high level of radiation to which the medical personnel were exposed. Therefore, the development of the remote afterloading technique in 1964 was essential for the widespread application of brachytherapy [29]. The introduction of the iridium-192 radioisotope with the possibility of delivery with a HDR, and the refinement of the afterloading apparatus by using automated, computer controlled steering devices, has led to significant progress [30]. The small size of the iridium source with its high activity ( $\sim 10$ Gy at the beginning of the treatment) and HDR allows its placement in a hollow guidance catheter, which can be easily placed endoluminally by a flexible bronchoscope. Nevertheless, it was not until the widespread use of the neodymium yttrium-aluminium-garnet (Nd-YAG) laser recanalisation of tumour stenoses that endoluminal brachytherapy was used more frequently for the palliative treatment of endobronchial and parabronchial tumours. Here, brachytherapy stabilises the recanalising effect of Nd-YAG laser therapy. It can be used, either alone or in combination with other methods, in a more curative setting, such as early stage endobronchial tumours.

Performed by an experienced endoscopist, HDR brachytherapy has the same acute side-effects as routine fibreoptic bronchoscopy and, therefore, can be easily applied in an outpatient setting. Irradiation lasts only a few minutes.

\section{Principles}

Brachytherapy is a form of radiation therapy, where the irradiation source with a high dose is either within or very close to the malignant tissue. The primary radiation produced is gamma rays. The physical characteristics of these radioactive 


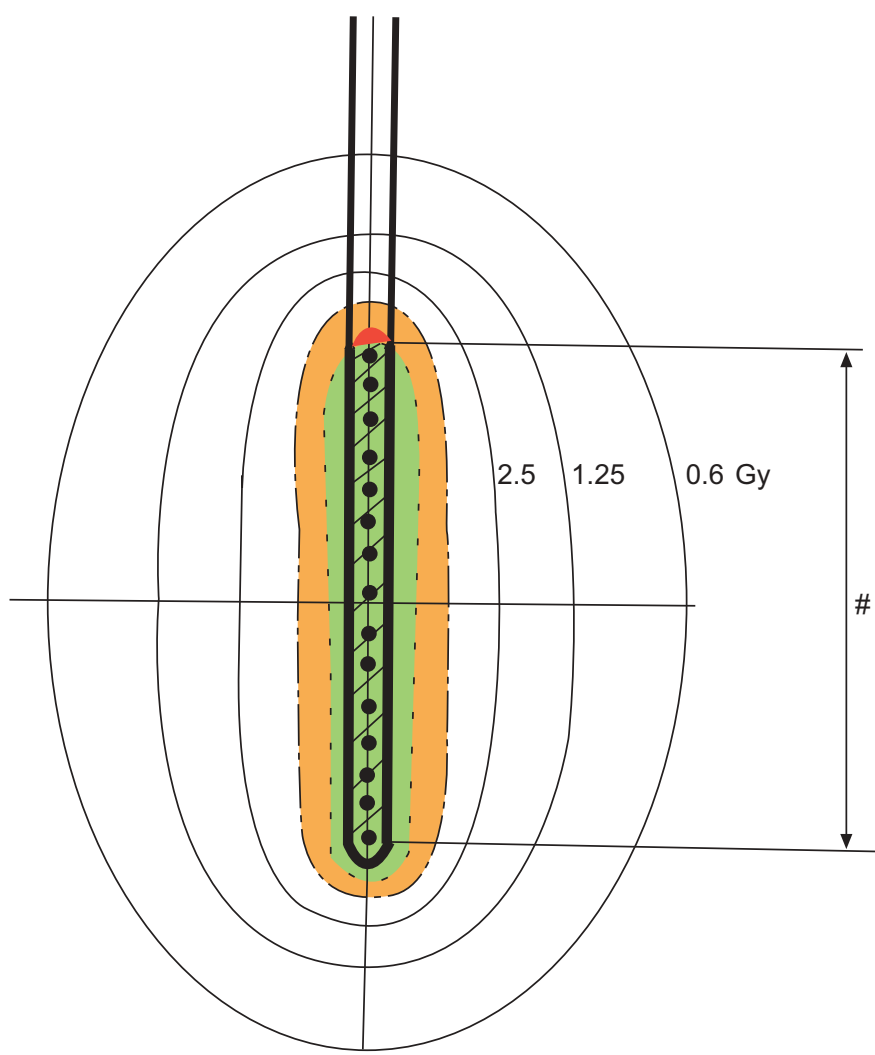

FIGURE 8. The principle of isodoses in high dose-rate brachytherapy. Orange: 5 Gy; green: 10 Gy. ${ }^{\#:} 7 \mathrm{~cm}$.

isotopes are characterised by the inverse square law which means that the dose rate decreases as a function of the inverse square of the distance to the source centre. This makes it possible to achieve a high irradiation dose in the centre of the irradiation source with a fast decrease towards the periphery. A typical distribution of isodoses is shown in figure 8. Usually the effects of irradiation are not direct killing of the cells, but single chain breaks of the DNA resulting in apoptosis and a decrease in cell proliferation. Therefore, the visible effects of brachytherapy with iridium-192 HDR are delayed, with the maximum visible and histological changes taking place $\sim 3$ weeks after application. These effects are clearly less pronounced in normal, nonmalignant tissue [31,32].

\section{Materials and methods}

\section{Devices}

To position the radiation source an afterloading polyethylene probe is used, which is available in different diameters, usually 2-3 mm in external diameter. A removable dummy simulates the pathway of the radiation source during the radiologically controlled placement of the probe (fig. 9). A vascular guide wire is helpful for placing the catheter and a tube, such as a shortened gastric tube, is helpful in avoiding direct contact with the normal tissue [33]. Centring devices, such as balloons, cages or sheaths, can be employed to maintain the radioactive source within the centre of the bronchial lumen and avoid dose inhomogeneity [34]. A HDR source with high activity of iridium-192 is usually used for endoluminal brachytherapy of thoracic malignancies. Remote brachytherapy is performed in

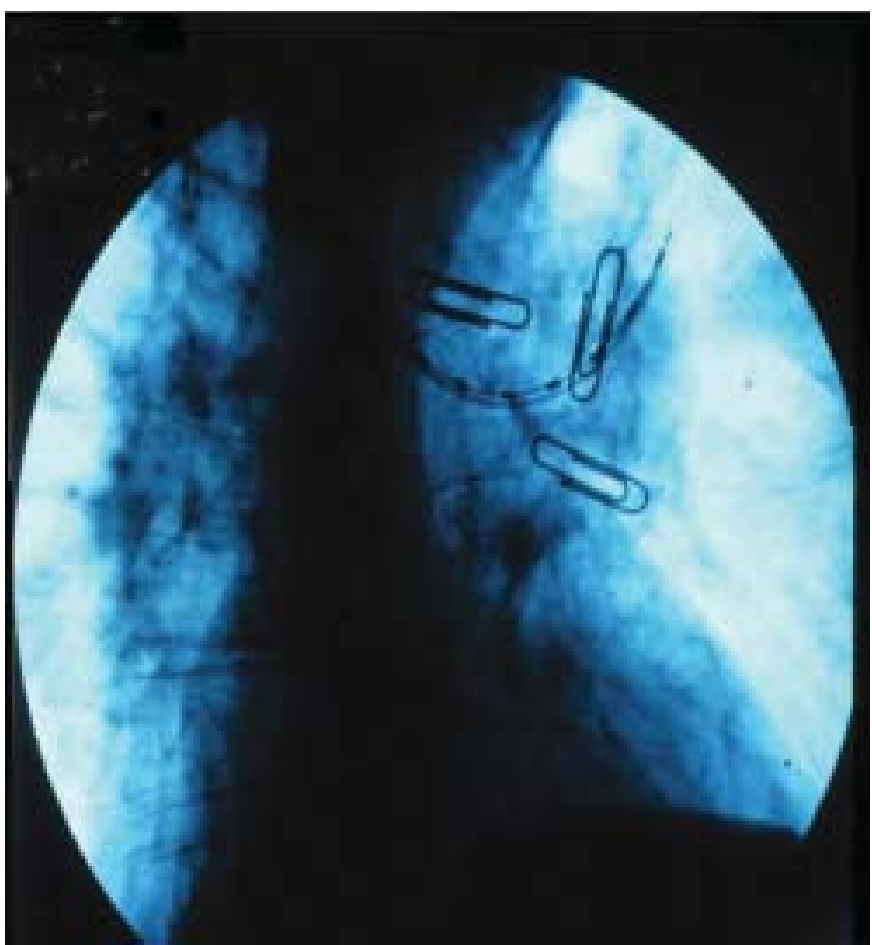

FIGURE 9. Placement of the afterloading catheter in the left upper lobe of the lung.

a shielded room with permanent oxygen delivery to the patient, who is monitored from outside by continuous assessment of oxygen saturation, pulse rate or electrocardiogram and direct visual control via a video camera. After removal of the dummy seed, the applicator is connected to the iridium-192 remote afterloading unit containing the irradiation source. The radiation source (diameter of $\sim 1 \mathrm{~mm}$ ) is advanced to the intended position under computer control and then drawn backwards at intervals of $5 \mathrm{~mm}$. It remains in each position for the time needed to apply the computed dose. By varying the source position and dwelling time, individual computer-assisted dose distribution can be achieved (fig. 10). The treatment can be interrupted and restarted whenever necessary.

\section{Energy levels, dosages and fractionation}

Until the mid 1980s a low energy radioactive source for brachytherapy was used. Now sources with higher energy are available, usually iridium-192. A distinction between radiation with different energy levels can be made using the terms low dose rate (LDR), medium dose rate and HDR. LDR brachytherapy implies delivery of $<2 \mathrm{~Gy} \cdot \mathrm{h}^{-1}$ and a total dose of 1,500$5,000 \mathrm{cGy}$, given over a period of up to 3 days [8]. Intermediate dose rates range $\sim 2-10 \mathrm{~Gy} \cdot \mathrm{h}^{-1}$ [35]. The International Commission of Radiation Units defines HDR as the application of $>20$ $\mathrm{cGy} \cdot \mathrm{min}^{-1}$ ( $1 \mathrm{rad}=1 \mathrm{cGy}$ ), which means a delivery of $>12 \mathrm{~Gy}$. $\mathrm{h}^{-1}$, with the dose per session (fraction) varying from $\sim 300-$ $1,000 \mathrm{cGy}$ (calculated at $10 \mathrm{~mm}$ from the source axis) [36].

Iridium-192 is the most commonly used source. As the source is in position for a shorter time, there is less chance the catheter will be displaced. A shorter treatment time also improves 


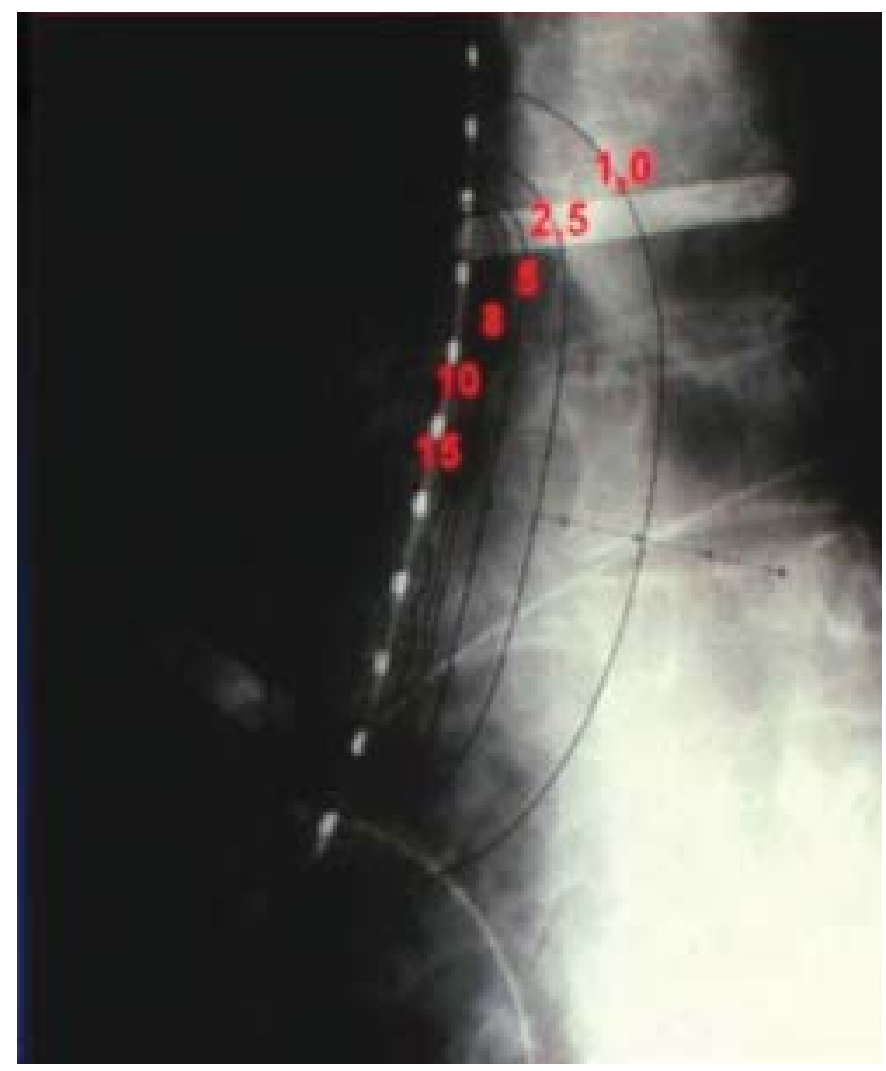

FIGURE 10. Treatment planning with isodose distribution (values are in Gy).

patient tolerance and reduces treatment costs. In contrast to LDR, HDR brachytherapy is usually delivered in a series of dose fractions in order to optimise its effectiveness and minimise side-effects. A wide variety of treatment schedules have been utilised; generally patients are treated no more than every 1-2 weeks because of the discomfort and logistical difficulties associated with more frequent bronchoscopies. There is only one controlled, randomised study to evaluate the effect of dose rate, overall radiation dose, fractionation and localisation of the afterloading catheter to survival rate, local control and complications. In the study [37], two treatment regimens with a comparable total irradiation dose of $15 \mathrm{~Gy}$ (at $1 \mathrm{~cm}$ from the source axis), but different doses per fraction (four fractions of 3.8 Gy on a weekly basis versus two fractions of 7.2 Gy at a 3 week interval) were compared. There were no disadvantages for the shorter fractionation regimen, with a similar survival time (19 weeks) and local control time in both groups. The complication rate was also similar, with fatal haemorrhage occurring in $\sim 21 \%$ of all patients.

\section{Methods}

In general, endoluminal brachytherapy using flexible bronchoscopy and an HDR regimen can be performed on an outpatient basis, as it is no more strenuous for the patient than a diagnostic bronchoscopy. In the case of LDR brachytherapy, hospitalisation for several days is usually required.

\section{Preparations for the procedure}

Flexible bronchoscopy is performed to localise the tumour region for irradiation. The afterloading catheters have an external diameter of $2-3 \mathrm{~mm}$. If there is subtotal stenosis of the bronchi due to submucosal or exophytic tumour growth, it is sometimes necessary to perform balloon dilatation or use other recanalisation methods for better applicator placement. If there has been previous laser treatment, it is recommended to wait $\geqslant 3$ days before brachytherapy treatment can be initiated, although the debate about this issue is still ongoing [38, 39]. Endoluminal irradiation should be delivered with a safety margin of $\geqslant 1 \mathrm{~cm}$ at both ends of the visible endobronchial tumour length. The active length refers to the distance between the first and last dwelling point of the iridium source in case of HDR brachytherapy. As the distal end of the tumour cannot always been seen by the bronchoscopist, the distal end-point of the irradiation length must often be estimated from previous chest radiographs or computed tomography scans and controlled during bronchoscopy by fluoroscopy.

\section{Placement of the applicator}

The irradiation length is marked by external tags controlled by fluoroscopy. A guide wire is placed through the working channel of the bronchoscope, which is then removed. Manipulation of the guide wire and then of the applicator through a partially obstructed lumen requires skill, particularly within the upper lobe bronchi. However, with this technique areas can be reached that cannot easily be reached by other recanalising methods. For a better fit of the afterloading probe, a shortened gastric tube with an external diameter of $5 \mathrm{~mm}$ is usually inserted over the guide wire by the Seldinger technique. The gastric tube should be placed inside the tumour bulk. The irradiation applicator is then placed into the tube and taped to the tip of the nose to prevent it from being dislocated. This should be carried out under visual fluoroscopic control.

After placement of the afterloading probe, a dummy seed is inserted, and a set of orthogonal chest radiographs is obtained to document the correct placement of the catheter within the tumour bulk and to determine the necessary irradiation length, as indicated by the external tags (fig. 9). The treatment dose is prescribed by the radiation oncologist, usually specified at a depth taken $1 \mathrm{~cm}$ from the middle of source axis [40]. One of the technical challenges is the obvious difference in luminal diameters of different segments of the tracheobronchial tree. It is uncommon to adjust for these differences, but SAITO et al. [41] attempted to answer this problem by setting distinct diameters at different segments of the tracheobronchial tree and adjusting the dose evaluation point to the lumen diameter at the lesion site.

After removal of the dummy seed, the applicator connected to the iridium irradiation source (diameter $\sim 1 \mathrm{~mm}$ ) is advanced to the intended position under computer control, then drawn backwards at intervals of $5 \mathrm{~mm}$. The source remains in each position for the time needed to apply the computed dose. By varying the source position and dwell time, an individual computer-assisted dose distribution can be generated (fig. 10).

\section{Follow-up}

The maximal effect of a brachytherapy session is seen after $\sim 3$ weeks. Therefore, a follow-up bronchoscopy is usually performed 3-6 weeks after the end of the planned treatment series. 


\section{Indications and complications of brachytherapy} Indications

The effects of brachytherapy are delayed. First effects can be seen after $\sim 1$ week, and the maximum effect is only achieved after $\sim 3$ weeks. However, brachytherapy probably has a longer-lasting effect and has greater tissue penetration than other tumour lysis techniques. It also destroys tumour outside of the bronchial wall and behind cartilage. HDR brachytherapy has the advantage of delivering a high dose of radiation over a short period of time to the tumour area without significantly affecting the adjacent lung parenchyma.

This technique is not indicated to achieve immediate debulking of an obstructive tumour. Therefore, in central tumours with imminent tracheal or bronchial occlusion, methods which rapidly destroy the tumour or stenting have to be applied. Thereafter, brachytherapy can be performed to achieve a longer-lasting effect on the tumour both inside and also outside the bronchial wall. Contraindications to endobronchial brachytherapy include the presence or the imminent danger of fistulas between bronchi and other structures.

\section{Palliative setting}

In most cases, brachytherapy is applied in a palliative setting. This is the case in metastatic diseases of patients with poor performance status. HDR endobronchial brachytherapy is then considered a palliative technique for alleviating dyspnoea resulting from major airway obstruction by primary and secondary malignant tumours. It is also indicated to palliate symptoms, such as cough, haemoptysis and dyspnoea, in patients who have received their maximal dose of EBRT.

\section{Curative indications}

Brachytherapy can be applied after surgery if there are microscopically positive resection margins.

Brachytherapy can also be used as an endobronchial boost to EBRT [41-45]. HDR brachytherapy has been primarily used for previously untreated patients in conjunction with EBRT, often to quickly relieve obstruction and to reduce the volume of irradiated normal lung tissue. Brachytherapy can help to reduce the permanent fibrosis of normal lung tissue due to large external irradiation fields, particularly when atelectasis due to obstruction of a main or lobar bronchus is obscuring the true tumour margins. It has been calculated that this procedure can reduce the irradiation of normal tissues by an average of $32 \%$ [46]. Apart from treatment for local stenosis,
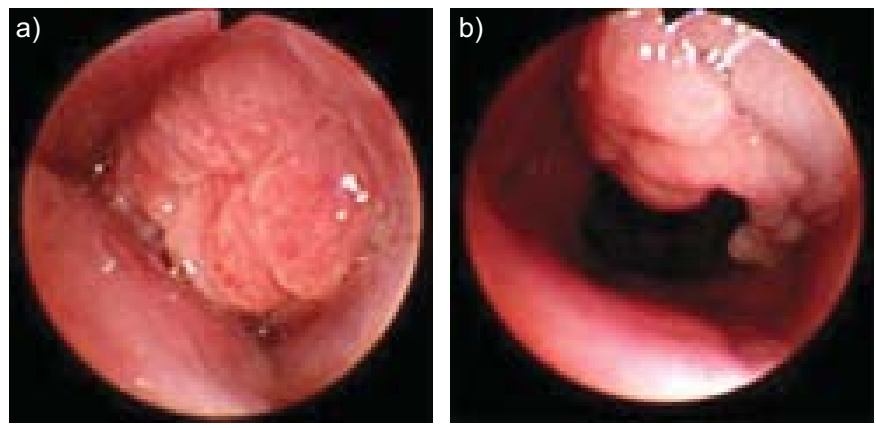

FIGURE 11. Tumour a) before first brachytherapy session and b) 3 weeks later (before the second session) brachytherapy has the potential to increase local control and survival time when used in combination with external irradiation. Although none of the studies published so far could demonstrate a clear advantage in terms of survival in nonselected patients treated with this combined modality, there are indications that at least local control is better in patients with additional endoluminal brachytherapy [47].

In very early superficial cancers, brachytherapy may be curative. Surgical resection is widely accepted as the treatment of choice in early stage nonsmall cell lung cancer (NSCLC). However, when occult carcinoma in situ or small invasive endobronchial lesions are discovered incidentally by bronchoscopy, mostly due to symptoms like cough or haemoptysis, HDR brachytherapy, either alone or as a boost to EBRT [41], offers a treatment option with good results, low morbidity, low cost and little inconvenience for the patient. Especially in carcinoma in situ or limited invasive tumours without nodal involvement, HDR brachytherapy could represent the definite treatment due to the deeper and unrestricted penetration. As with other treatment modalities, data published on intraluminal brachytherapy in early stage NSCLC are limited [41, 47-51].

\section{Nonmalignant indications}

HDR brachytherapy can also be used for nonmalignant tracheal and bronchial obstruction. Typical applications are the treatment of recurrent granulation tissue formation in and around a stent or of granulation tissue at the bronchial anastomosis after lung transplantation [52, 53].

\section{Effectiveness}

In palliative indications, overall improvement and disappearance of symptoms has been shown in $65-95 \%$ of all patients. Haemoptysis can be treated with a high rate of success; this is also true for the reopening of obstructed bronchi. Improvement of cough, shortness of breath and pain was observed to a lesser degree. Palliation can be maintained in a high proportion of patients [35, 39, 43, 45, 54,55]. This can also be verified by bronchoscopy (fig. 11a and b) or lung function testing [56-58]. There are even hints for survival advantage in selected cases $[42,59]$.

\section{Complications}

Acute side-effects of the placement procedure include severe coughing and increased bronchial secretion. They are not more frequent than those occurring during routine diagnostic flexible bronchoscopy. The placement of the afterloading catheter and the following remote irradiation procedure in the HDR setting are usually well tolerated. However, patients with poor performance status and severe respiratory failure are at higher risk due to the prolonged procedure.

Temporary pleuritic pain or even pneumothoraces have been described when the guide wire or the applicator were placed too vigorously. However, the present author has never observed such serious side-effects during $>2,000$ placements of afterloading probes.

As with EBRT [59], radiation bronchitis and stenosis may occur days or weeks after therapy and can manifest with cough or wheezing (fig. 12). Histological changes consist of mild mucosal inflammation to severe bronchial fibrosis. Risk factors 


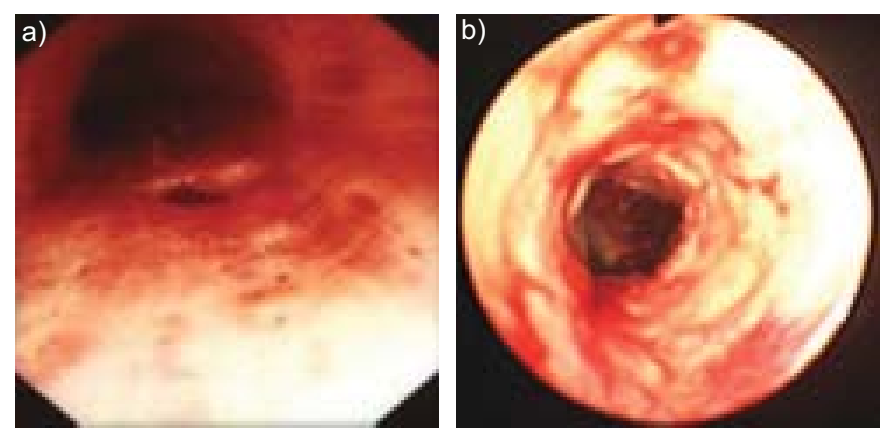

FIGURE 12. a) Radiation bronchitis and b) stenosis.

include large cell carcinoma histology, use of brachytherapy for curative intent, prior laser resection and concurrent external beam radiation [35]. Overall bronchial stenosis has been shown to occur in $\sim 10 \%$ of patients after HDR EBRT for lung cancer [60]. Therapy of these post-radiation effects consists of conventional treatment, such as inhaled steroids and antibiotics, or, for stenosis, balloon dilatation, laser resection and stenting.

The most important potential side-effects of brachytherapy are fatal haemoptysis and fistula formation. Such adverse outcomes are reported in $0-32 \%$ of patients, with an overall prevalence of $\sim 10 \%$ [56]. For the interpretation of these figures, it should be kept in mind that most of the studies published are not randomised and are not even prospective. The studies use different selection criteria concerning pre-treatment, catheter placement, dosages, fractionation, localisation and histology. The occurrence of fatal haemoptysis is usually considered as a complication of treatment and not related to the disease itself. However, the data on the natural course of lung cancer is sparse and it is often difficult to differentiate between treatment complications and tumour progression. One can argue that the incidence of fatal haemoptysis is related, for example, to tumour invasion into pulmonary vessels or related to the administered irradiation dose and fractionation regimen or even to the longer survival of the patients who receive brachytherapy. Squamous histology and tumour localisation in the mainstem bronchi predispose to fatal haemorrhage [61, 62]. This localisation represents a further negative selection towards more frequent haemorrhages. It is possible that the combination of external and endoluminal irradiation increases the frequency of haemorrhages. However, one randomised trial could not demonstrate a statistically significant difference in comparison to external radiotherapy alone [27]. One of the relevant factors for haemoptysis is the localisation of the radiation, especially the direct contact between the endobronchial brachytherapy applicator and the tracheobronchial walls at the vicinity of the great vessels [63]. Furthermore, an increase of the dose per fraction over $10 \mathrm{~Gy}$ at a distance of $10 \mathrm{~mm}$ from the source axis increases the risk of bleeding dramatically [64].

In general, the incidence of fatal haemorrhage is high and all efforts to minimise potential side-effects of endobronchial brachytherapy should be strengthened. However, with usual dosages and fractionation, fatal haemorrhage seems to be correlated more with the natural course of a longer survival than with endoluminal brachytherapy itself.
Overall, endobronchial brachytherapy is easy to perform in an outpatient setting with little discomfort to the patient and can be considered a well-tolerated treatment option, especially in patients with reduced performance status.

\section{Combination with other endobronchial methods and chemotherapy}

Adding brachytherapy to Nd-YAG laser therapy improves the local control [65]. Furthermore, the combination of laser therapy and brachytherapy in early lung cancer seems to offer a significant survival advantage over either therapy alone [66]. This is also reported for the combination of HDR brachytherapy after 6 weeks with PDT [67]. The combination with systemic chemotherapy is feasible and seems to provide radiosensitisation [68].

\section{Conclusion}

Bronchoscopic brachytherapy in its HDR form is an easy-toperform outpatient treatment for endoluminal and paraluminal tumours. It is effective in palliating symptoms such as dyspnoea, haemoptysis, intractable cough, atelectasis and post-obstructive pneumonia. Brachytherapy can be combined with all other modalities of tumour therapy, e.g. external beam radiation, Nd-YAG laser therapy, PDT or chemotherapy and may improve the degree and duration of palliation. Small tumours can be cured by brachytherapy. Unfortunately, as with other endobronchial treatment modalities, experience is limited and further randomised studies are needed. Brachytherapy is a permanent interdisciplinary challenge with the need of a close contact between radiation oncologists and chest physicians. Further investigations are necessary to determine optimal dose fractionation and the ideal adjunctive use of the technique.

\section{PHOTODYNAMIC THERAPY \\ Background}

The healing power of sunlight and the therapeutic effects of light-activated chemical compounds have been recognised throughout history and by ancient civilisations [69]. However, the scientific basis of light treatment (phototherapy) is rooted in the 20th century. In the early 20th century, FINSEN [70], a Danish physician, noted that tuberculous lesions occurred more frequently during the winter season. This prompted him to study the effects of light in a number of conditions, notably smallpox and the cutaneous form of tuberculosis, lupus vulgaris, which at the time occurred commonly in Scandinavia. FINSEN [70] harnessed light in the ultraviolet spectrum from sunlight and from electric arc lamps and thus laid down the foundation of phototherapy; in 1903 he was awarded the Nobel Prize in Physiology and Medicine for his work. There followed the establishment of departments of light therapy, known as Finsen Therapy, in many city hospitals throughout the world, most notably in Copenhagen (Denmark) where The Medical Light Institute was named after him.

Parallel with the development of Finsen's phototherapy, other scientists were focusing their attention on the biological effects of light-activated chemical compounds (photochemotherapy) on living tissue. In this area, RAAB [71] and VON TAPPEINER and co-workers [72-74] were examining the effect of chemical compounds on infusoria. They made a number of observations, of which two were seminal in the development of PDT. 


\begin{tabular}{|c|c|}
\hline $\begin{array}{l}\text { Evolutio } \\
\text { of treatr }\end{array}$ & $\begin{array}{l}\text { n of photodynamic therapy and definition } \\
\text { ments involving light }\end{array}$ \\
\hline Treatment & Definition/component \\
\hline Heliotherapy & Use of sunlight for treatment \\
\hline Phototherapy & Treatment using specific light (e.g. ultraviolet) \\
\hline Photochemotherapy & $\begin{array}{l}\text { Treatment using specific light and } \\
\text { chemical compound, and nonspecific light, } \\
\text { usually in the presence of air/oxygen }\end{array}$ \\
\hline \multirow[t]{4}{*}{ Photodynamic therapy } & $\begin{array}{l}\text { Treatment using chemical photosensitising } \\
\text { agent (drug) }\end{array}$ \\
\hline & + matching specific wavelength light \\
\hline & (laser/nonlaser, i.e. collimated/noncollimated light) \\
\hline & + oxygen (present in living tissue environment) \\
\hline
\end{tabular}

They noted that the chemical compound acridine could affect the biological behaviour of paramecia and that the organism was killed when the preparation was exposed to daylight. They also discovered that air (oxygen) was necessary for the death of paramecia in the acridine plus light setting. These authors referred to the phenomenon as "Photodynamisch Wirkung" (photodynamic reaction/effect). During the 1960s and 1970s, experimental and clinical PDT evolved from these and subsequent observations, with the first recorded case of clinical PDT reported by LIPSON et al. [75] in 1966. The case was a large recurrent ulcerating breast tumour treated by injection of haematoporphyrin derivative (HPD) followed by exposure to a filtered xenon arc lamp.

In the 1970s, a number of investigators were working on the photodynamic effects of different chemicals and their corresponding activating light. HPD and light in the red spectrum appeared as the most suitable combination to yield photodynamic action in the animal model and clinical situation [76, 77]. DOUGHERTY et al. [78] showed that systemic administration of HPD followed by exposure to red light from a xenon arc lamp could eradicate transplanted murine mammary tumour without much change to normal tissue surrounding the tumour. This same group started clinical trials in 1976 at Roswell Park Memorial Institute (Buffalo, NY, USA), which showed the effectiveness of PDT in a variety of malignant growths [76, 78, 79].

Bronchoscopic PDT began in 1982 at Tokyo Medical University (Tokyo, Japan), when HAYATA et al. [80] treated a patient who had an operable early lung cancer but refused surgical intervention. The treatment was carried out with complete eradication of the tumour. After nearly 4 yrs the patient died from noncancer-related causes [81].

At that time, many of the PDT clinical trials were focused on cutaneous and subcutaneous cancer. Nevertheless, by virtue of its high incidence, advanced stage of disease at presentation and highly unresectable rate, lung cancer became one of the first cancers to be targeted for PDT trials [82-85].

This brief history demonstrates how clinical PDT evolved through phototherapy and photochemotherapy (table 1).

\section{Definition and mechanism of action of PDT in cancer}

PDT is a treatment method which relies upon the excitation of a chemical photosensitiser (the drug) by an appropriate light whose wavelength matches the absorption band of the drug. Oxygen is essential in PDT, since the photodynamic reaction, leading to cell necrosis, depends on the release of singlet oxygen and the generation of other oxygen-dependent cytotoxic agents. The mechanism involved in cancer destruction and tumour necrosis in PDT has been the subject of continuing research for over 30 yrs. The observations by VON TAPPEINER and colleagues [72-74] in the early 20th century were the initial basic steps that led to the description of photodynamic effect showing the destructive power of the photodynamic phenomenon. However, whilst the mechanism of death in a simple organism, such as infusozia, depends on direct cytotoxity of a light-activated chemical, in a complex multisystem species, as is the case for mammalians, such tissue destruction would be expected to rely on a number of additional factors. In the human species, the mechanism of PDT action, and cell death resulting from it, appears to be mediated through the following. 1) Generation of singlet oxygen and other toxic reactive oxygen species resulting from light and the photochemical interaction with oxygen. 2) Direct damage of subcellular and biomolecular structures of the cell. 3) Indirect ischaemic effects and injuries resulting from vascular shut down of affected tissue. 4) Indirect effects of the light-activated chemical and promotion of inflammatory and immune response. 5) Apoptosis.

It therefore appears that the mechanisms of photodynamic reaction are both direct, through disturbed cellular metabolism, and indirect, mediated by vascular and extracellular fluid, which constitutes the cell environment's "milieu interior".

\section{Method}

Bronchoscopic PDT for lung cancer is carried out as a twostage procedure, namely, photosensitisation and illumination.

\section{Photosensitisation stage}

This stage is achieved by an intravenous administration of a suitable photosensitiser (the drug) to the patient. The first photosensitiser used for bronchoscopic PDT was derived from the porphyrin family. HPD was used systemically by intravenous injection at variable dose rates $\left(2-4 \mathrm{mg} \cdot \mathrm{kg}^{-1}\right.$ body weight) [85]. After manipulation and purification, HPD was commercialised for clinical use under the labels Photofrin ${ }^{\circledR}$ (Axcan Pharma Inc., Houdan, France) and Photosan ${ }^{\circledR}$ (Seehof Laboratorium Forschungs- und Entwicklungsgesellschaft $\mathrm{mbH}$, Wesselburenerkoog, Germany), to name but a few. Photofrin ${ }^{\circledR}$ (Porfimer Sodium) is licensed for use in advancedstage lung cancer by the Food and Drug Administration and European Union Licensing Authorities. At the present time, Photofrin ${ }^{\circledR}$ is the most commonly used photosensitiser for bronchoscopic PDT and has a long-standing safety record [69, 85-87]. The recommended dose of Photofrin ${ }_{\circledR}$ is $2 \mathrm{mg} \cdot \mathrm{kg}^{-1}$ body weight. At this dose, the drug is safe, reliable and nontoxic. However, it is not highly selective and indiscriminate illumination could result in collateral damage to normal adjacent areas with oedema and inflammation of the bronchial walls. 

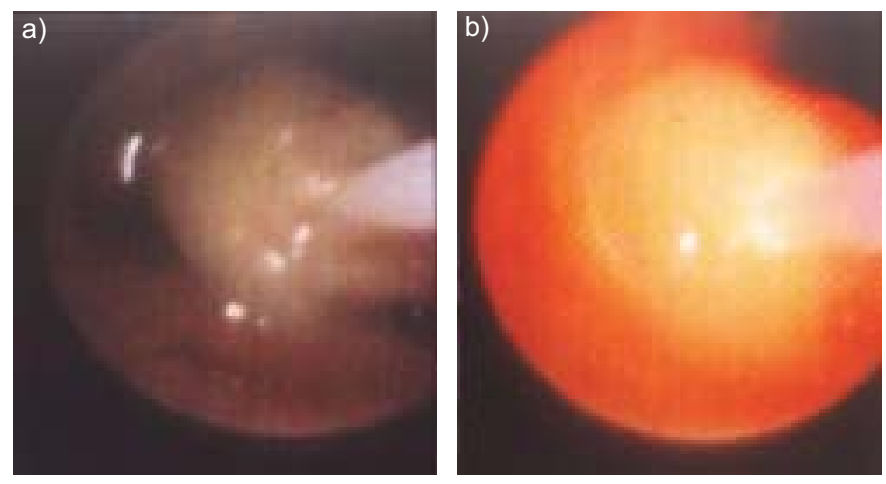

FIGURE 13. Tumour mass in the right upper lobe a) with cylindrical diffuser in the tumour and b) with illumination in progress.

\section{Chlorin family}

Porphyrin-based photosensitisers were the first-generation sensitisers used for bronchoscopic PDT. Many other sensitisers have since been prepared and tested in the laboratory setting; although most have not reached clinical trial, a few have. Amongst the latter is meta-tetra(hydroxyphenyl)chlorin (Foscan $\mathbb{R}$; Scotia Pharmaceuticals, Stirling, UK), which is not commonly used for bronchoscopic PDT. One group has employed Foscan ${ }_{\circledR}$ in a series of patients with apparent success and no major drawbacks [88]. However, detailed information on its use for bronchoscopic PDT has not been published.

\section{Illumination}

Illumination consists of bronchoscopic exposure of the presensitised tumour to a light of a specific matching wavelength. The overall effect is necrosis of the tumour. There are essentially two methods of illumination: interstitial and surface illumination. In the former, the light exposure is from within the tumour mass; in the latter, the exposure is over the surface of the tumour (fig. 13a and b).

\section{Light sources}

Photodynamic reaction is dependant on activation of the photosensitiser by a light of appropriate wavelength. The key to photodynamic reaction is the match between a specific wavelength of light and the absorption band of the chemical photosensitiser. The latter locks with the light and starts a chain reaction, which results in necrosis and cell death. The light which activates a porphyrin-based photosensitiser is within the red region of the spectrum $(630 \mathrm{~nm})$. A number of light sources have been used to deliver this red light to the tumour, including argon/dye lasers, metal vapour lasers and, more recently, diode lasers [89]. For other photosensitisers, there are also diode lasers generating light of appropriate matching wavelength.

\section{Light delivery system}

The light generated and emitted by a laser is delivered to the endobronchial tumour by optical fibres with either a cylindrical diffusing tip or a micro-lens. Cylindrical diffusers distribute light circumferentially and may be used for interstitial treatment when the diffuser is placed within the tumour mass. The micro-lens emits forward-firing light and is employed for surface application to treat superficial growth
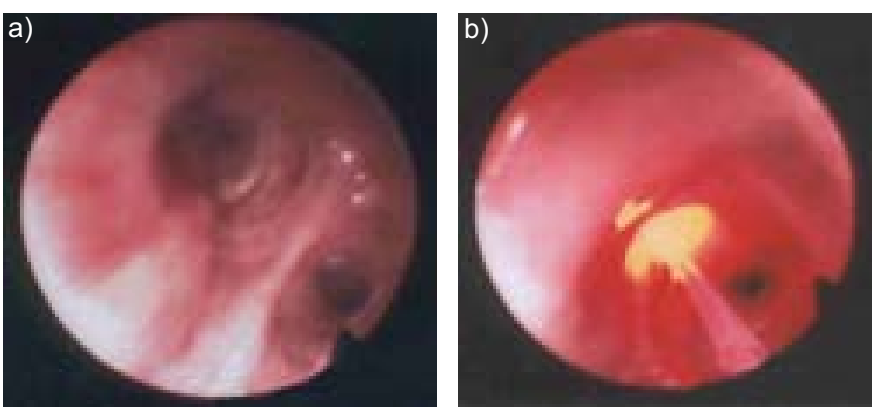

FIGURE 14. a) Bronchoscopic view of an early cancer and b) with surface illumination.

(fig. 14a and b). In either case, the delivery fibre is introduced via the biopsy channel of the fibreoptic bronchoscope, which provides access to the tumour (fig. 15). The light dose at its point of delivery is calculated to be $200 \mathrm{~J} \cdot \mathrm{cm}^{-1}$ of lesion or the equivalent length of the delivery device [89]. This is usually made up of $400 \mathrm{~mW} \times 500 \mathrm{~s}(1 \mathrm{~J}=$ power $(\mathrm{mW}) \times$ time $(\mathrm{s}))$.

\section{Anaesthetic and instrumentation}

The route of access for illumination of pre-sensitised endobronchial cancer is the biopsy channel of a flexible fibreoptic bronchoscope (FFB), which accommodates the light delivery optical fibre. Such bronchoscopic illumination can be achieved by one of the following two methods. Method 1 uses FFB under topical anaesthetic and sedation with the patient breathing normally. This is similar to diagnostic bronchoscopy as practiced by bronchoscopists. Method 2 uses general anaesthesia and controlled positive pressure ventilation by a jet ventilator or by hand-controlled injector. In this method, the open-ended rigid bronchoscope is first placed in the trachea for ventilation. The FFB is then introduced through the bronchscope for precise visualisation of the lesion and illumination (fig. 15).

Each method has advantages and disadvantages (table 2). The use of general anaesthetic necessitates the presence of an anaesthetist and more elaborate equipment, but provides a comfortable environment for the patient and facilitates the operative procedure. General anaesthesia and use of the rigid instrument allows the operator more time, better access to lesions and less risk of displacement of the delivery fibre in patients with bulky tumours and/or multiple lesions. However, a unifocal superficial lesion of limited extent can easily be treated using FFB under topical anaesthesia. In the present author's experience, the use of the combined rigid and flexible instruments under general anaesthesia is best for patients with obstructive exophytic tumour of the major airway (trachea main stem bronchi), and should be recommended for such cases. For other cases the choice depends on the experience of the operator and patient choice.

Review of the literature concerned with bronchoscopic PDT [85] seems to indicate the following. 1) Many authors whose series consist predominantly of patients with advanced stage disease and endoluminal obstruction of major airways have employed general anaesthetic and its associated instrumentation. 2) Authors treating early superficial lesions have used topical anaesthetic and FFB. 
TABLE 2 Comparison of the two methods of illumination for bronchoscopic photodynamic therapy (see text for details)

\begin{tabular}{|c|c|c|c|c|c|c|c|c|}
\hline $\begin{array}{l}\text { Instrument } \\
\text { anaesthesia }\end{array}$ & $\begin{array}{l}\text { Ease and } \\
\text { comfort for } \\
\text { patient }\end{array}$ & $\begin{array}{c}\text { Ease of } \\
\text { operation }\end{array}$ & $\begin{array}{l}\text { Anaesthetic } \\
\text { risk }\end{array}$ & $\begin{array}{c}\text { Risk of OF } \\
\text { displacement/ } \\
\text { cough }\end{array}$ & $\begin{array}{c}\text { Clearance } \\
\text { of airway }\end{array}$ & $\begin{array}{l}\text { Dealing with } \\
\text { complication/ } \\
\text { accident }\end{array}$ & $\begin{array}{c}\text { Complexity of } \\
\text { equipment }\end{array}$ & $\begin{array}{c}\text { Post illumination/ } \\
\text { debridement }\end{array}$ \\
\hline FFB/topical & \pm & $\begin{array}{c} \pm \text { (time- } \\
\text { dependent) }\end{array}$ & \pm & + & -/possible & - (not adequate) & - & Difficult \\
\hline $\begin{array}{l}\text { Rigid }+ \\
\text { FFB/general }\end{array}$ & ++ & ++ & + & - & $+($ good) & ++ (very adequate) & + & Easy \\
\hline
\end{tabular}

\section{Bronchoscopic PDT in practice}

Patients selected for bronchoscopic PDT will have had standard lung cancer work up, including diagnostic bronchoscopy and confirmation by histo/cytology of the malignant tumour. Prior to photosensitisation, a further bronchoscopic examination is carried out using white light and fluorescence bronchoscopy (if available) in order to delineate the tumour and its extent (fig. 16a and b). It is important that the bronchial tree is examined in its entirety in order to map out synchronous lesions in adjacent or more distant sites from the main focus. After administration of the photosensitising drug, time is allowed for its absorption and its preferential retention in the tumour. The duration of this latent period depends, to a large extent, on the composition of the photosensitiser. For Photofrin ${ }^{\circledR}$, this is $24-72$ h. Following this period, bronchoscopic illumination is carried out. This consists of exposure of the pre-sensitised tumour (or all tumour sites) to laser light, as previously described.

\section{Post-PDT management}

Clearance of the airways, debridement

Immediately after illumination, attention should be paid to clearance of the airways and removal of debris (fig. 17) from the treated area and beyond with the use of biopsy forceps, followed by aspiration and lavage with normal saline solution. In patients with exophytic endoluminal obstructive tumours requiring interstitial treatment, it is necessary to carry out this

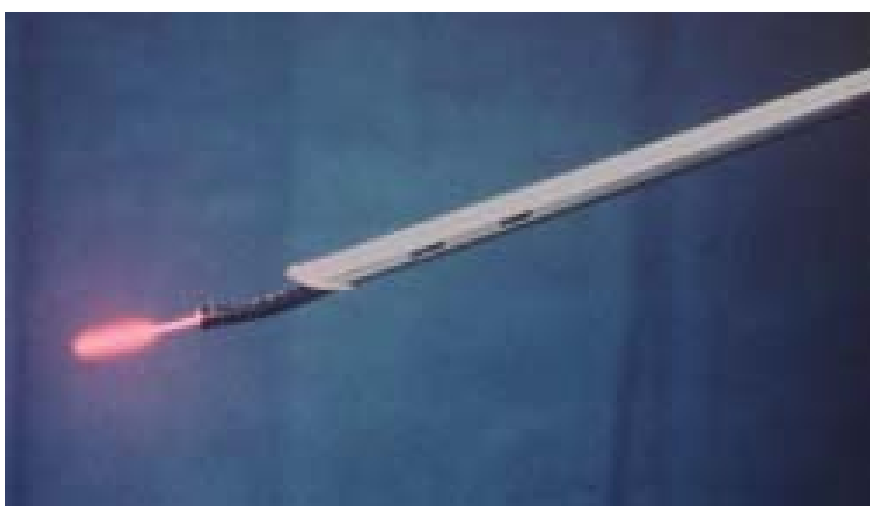

FIGURE 15. Bronchoscopic photodynamic therapy with the use of a combined rigid and flexible bronchoscope. Note the optical fibre with its end diffuser protruding through the biopsy channel of the fibreoptic bronchoscope for illumination. procedure not only immediately after illumination, but also a few days later. At this time, some necrosis of the tumour occurs, as well as discharge of infected secretions collected beyond the bronchial obstruction. Clearance of the airways in patients with bulky obstructive tumours is most effectively carried out with the use of the rigid bronchoscope and its accessories.

\section{Re-illumination}

It is important to consider re-illumination after post-PDT debridement when it is deemed necessary, i.e. when there are residual tumour islands. It should be emphasised that such illumination needs to be within the prescribed time (within 6-7 days of the intravenous injection of Photofrin ${ }_{\mathbb{R}}$ ) so that tumour tissue concentration of the photosensitiser (drug) is either at therapeutic level.

\section{Prevention of bronchopulmonary infection}

This is particularly relevant to patients with significant lobar or segmental tumour obstruction. In such patients, post-PDT necrosis creates a good culture medium for organisms in the airway, notably beyond the obstructive lesion. Physiotherapy, breathing exercise and, at times, a course of antibiotics may be required.

\section{Indications and patient selection for bronchoscopic PDT}

It is generally agreed that surgical resection is the treatment of choice for lung cancer when the tumour is oncologically and technically resectable, and provided that the patient is fit for
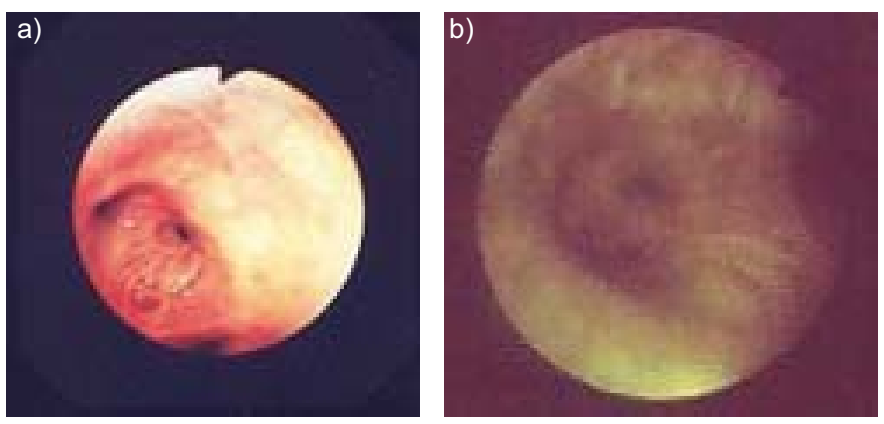

FIGURE 16. a) White light bronchoscopic view of a case of left upper lobe carcinoid. b) Fluorescence bronchoscopic view using Xillix LIFE-Lung Fluorescence Endoscopy System (Xillix Technologies Corp., Richmond, BC, Canada) of the same case showing more extensive mucosal alteration. 

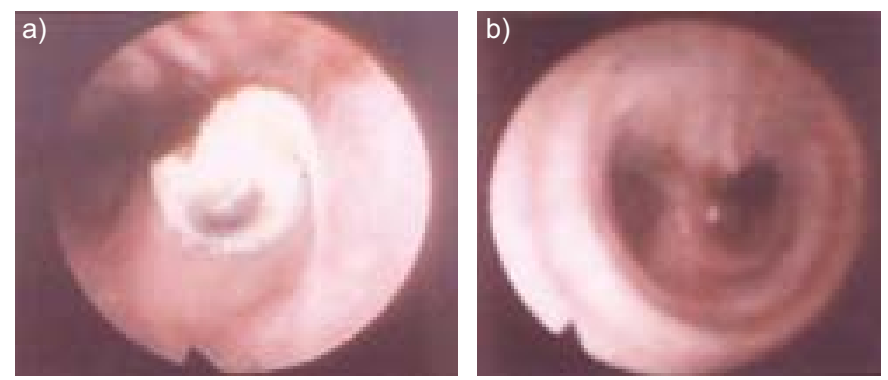

c)

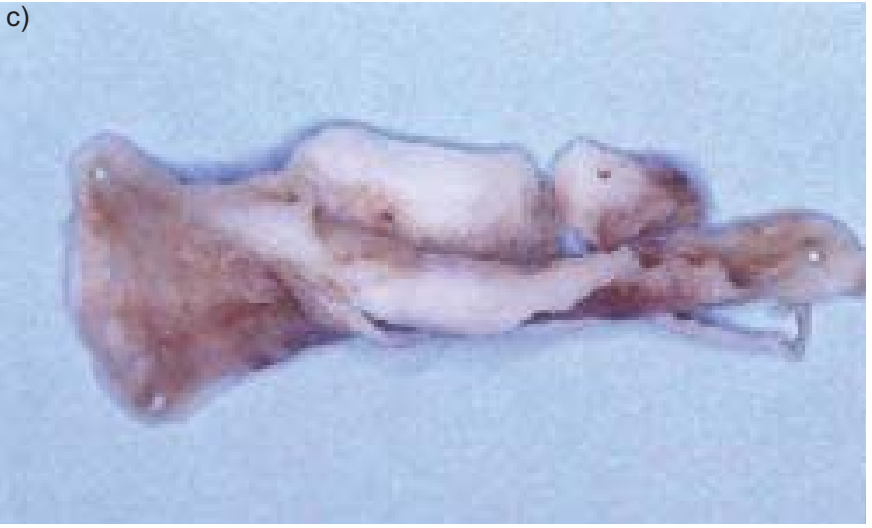

FIGURE 17. a) Bronchoscopic view showing tumour almost completely obstructing the right main bronchus. b) Clearance of the bronchus 1 month after bronchoscopic photodynamic therapy. c) Tumour debris mixed with a fibrin clot removed 1 week after bronchoscopic photodynamic therapy.

and consents to the operation. Considering this, it is also acknowledged that only a small proportion of patients, amounting to $\leqslant 15-20 \%$ of the lung cancer population, could qualify for resectional surgery. It therefore follows that $80-85 \%$ of lung cancer patients are classified as inoperable, either by the nature of their advanced stage disease, because of poor general condition or from choice. This is a huge population, amounting to $>25,000$ individuals per annum in the UK alone. In $50-60 \%$ of this population, the tumour is central, projecting into the bronchial lumen, is visible bronchoscopically and is diagnosable by bronchial biopsy. For the purposes of interventional bronchoscopy (including bronchoscopic PDT), the present author classifies these tumours as type I lung cancer, as opposed to type II cancer, which are peripheral tumours not directly diagnosable bronchoscopically.

The prerequisite for bronchoscopic PDT is the presence of a malignant endobronchial lesion confirmed by cytohistology. By implication, only patients with central (type I) lung cancer will qualify for PDT. Theoretically PDT is indicated in every patient with type I lung cancer if their general condition allows bronchoscopic operation. In practice, at the present time, selection for bronchoscopic PDT is made from subjects unsuitable for surgery (inoperable/unresectable patients) according to the extent and stage of their disease. These inoperable patients are divided into two groups. 1) Those with advanced stage disease (stages III and IV) [90] at presentation (group/subtype A). These patients are inoperable because they are oncologically unresectable. 2) Those with early stage disease (group/subtype E) with oncologically and technically
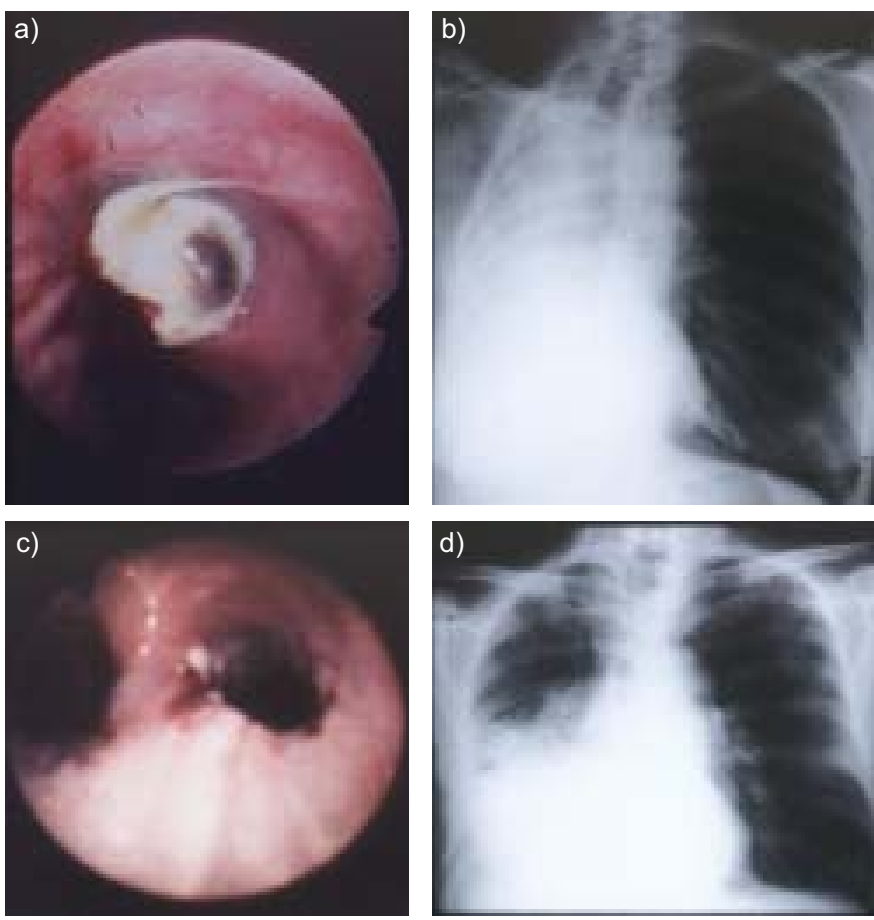

FIGURE 18. a) White light bronchoscopic view of an obstructive tumour in the right main bronchus. b) Pre-treatment chest radiograph of the same patient showing complete collapse (atelectasis) of the right lung. c) White light bronchoscopic view 1 week after treatment. d) Post-treatment chest radiograph.

resectable cancer but who are, for a variety of reasons, unsuitable for surgical resection.

PDT is indicated in both groups but with different objectives. For group A patients, the aim is palliation of symptoms, whereas for group E patients, the aim is survival benefit and curative intent.

\section{Group A patients}

The majority of patients in group A have an obstructive endobronchial lesion and are usually symptomatic with dyspnoea, cough and haemoptysis; the relief of obstruction will alleviate the symptoms (fig. 18). The initial trial of bronchoscopic PDT in the 1980s was directed towards symptomatic patients with endoluminal exophytic tumours causing major obstruction [83]. In the light of subsequent and more recent experience, PDT indications in this group have become more stringent. The present selection criteria consist of the following: 1) patients with inoperable/unresectable tumour with existing or impending related symptoms; 2) patients with good performance status (Karnofsky performance status index $>50 \%$ or World Health Organization (WHO) scale $\leqslant 3$ ); and 3) patients without extrathoracic metastatic disease.

Previous surgical operation, chemo-/radiotherapy or other endoluminal therapy do not constitute exclusion criteria. All histological types respond to PDT, including small cell cancer, provided that the lesion can be accessed bronchoscopically for illumination. 
TABLE 3 Mortality and morbidity of bronchoscopic photodynamic therapy (PDT)

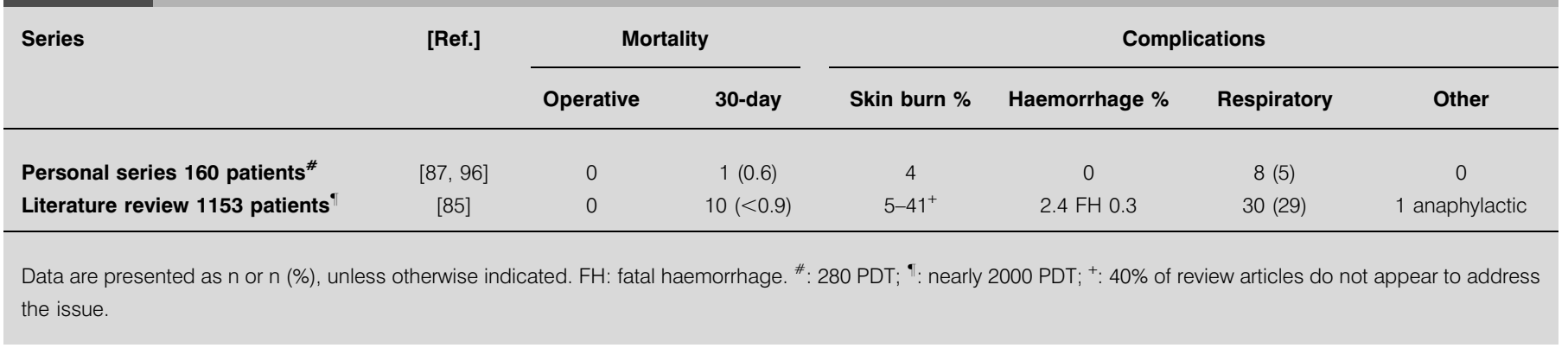

\section{Group E patients}

In the context of bronchoscopic PDT, the term early cancer is used to describe cases in which the tumour is limited in its extent to the bronchial tree and is confined in depth to the inner bronchial wall. It is important to emphasise that standard investigatory methods may not be capable of providing a precise diagnosis of early stage cancer according to the above definition. A carcinoma in situ involving superficial layers of bronchial epithelia can be radiologically occult and bronchoscopically invisible when examined using white light. It is also relevant to emphasise that a case with superficial synchronous (multifocal) endobronchial lesions should, for the purpose of bronchoscopic PDT, be considered as an early cancer even though, based on standard tumour node metastasis classification [90], it cannot be classed as stage I.

Two recently developed methods assist the bronchoscopic diagnosis of early cancer. Fluorescence bronchoscopy uses a blue light with greater discriminative power of differential fluorescence imaging than its white light counterpart. This more accurately displays mucosal abnormalities than white light bronchoscopy [91, 92] and is of use both for pre-PDT diagnosis of early endobronchial cancer and for monitoring response to treatment. The second development is endobronchial ultrasonography. This enables the imaging and estimation of the depth of bronchial wall involvement by the tumour [93-95].

At the time of writing, there is some consensus of opinion in respect of bronchoscopic PDT indications in early stage lung cancer. These are patients: 1) whose general condition puts them in such a high-risk category as to prohibit them being offered resectional surgery; 2 ) who have inadequate predicted post-operative (post-resection) pulmonary function (such patients may well recover from the operation but postoperatively they may become a respiratory cripple with unacceptably poor quality of life); 3) who have multifocal endobronchial early cancer whose surgical resection is either technically impossible or would entail too extensive a loss of pulmonary parenchyma; 4 ) who present with early stage metachronous cancer following previous extensive surgical resection; and 5) who decline surgical resection but consent to PDT.

Some patients with early lung cancer present with cough, blood-stained sputum and dyspnoea. The latter is not usually related to endobronchial tumours, but is associated with coexisting conditions such as chronic obstructive pulmonary disease.

\section{Results/outcome}

Bronchoscopic PDT results are evaluated using the following parameters: 1) mortality and morbidity; 2) local pathological response to treatment; and 3) patient satisfaction and clinical effect.

\section{Mortality and morbidity}

Over the years, experience has shown that bronchoscopic PDT is a safe treatment method. Technically the procedure can be mastered by the majority of bronchoscopists. There is no death associated with the procedure per se and the 30-day mortality rate (empirically set for surgical operations) is $<1 \%$ (table 3 ). A recent review article [85] concerning 25 publications from the world literature and comprising 1,153 patients undergoing nearly 2,000 bronchoscopic PDT procedures for cancer confirms this.

Important adverse reactions of bronchoscopic PDT are presented in table 3. The morbidity of bronchoscopic PDT relates greatly to skin burn, i.e. photosensitive reaction of the skin exposed to sunlight. This was reported to be $20 \%$ for bronchoscopic PDT with Photofrin ${ }^{\circledR}$ in a multicentre trial. Skin burn can be an important drawback and a prohibitive factor for clinical PDT, particularly in those cancer patients with limited life expectancy. Nevertheless, it should be emphasised that this is an avoidable complication whose incidence can be reduced considerably by thorough counselling and regular reminders to the patient to avoid exposure to sunlight. At the Yorkshire Laser Centre (YLC; Goole, UK), with a total of nearly 500 PDTs using a systemically administered photosensitiser, the incidence of skin burn in different series has consistently been 3.5$5.3 \%$ of patients. Furthermore, in the last 50 patients, no cases of skin burn have been recorded.

Other complications of bronchoscopic PDT reported in the literature are listed in table 3.

\section{Local pathological response to treatment}

By convention, local response to treatment is described as complete response/remission (CR) when a treated area becomes macroscopically and microscopically (by cyto/histology) clear from tumour. Partial response/remission (PR) occurs when macroscopic extent of the tumour is reduced by $\geqslant 50 \%$ after treatment, but cyto/histology demonstrates presence of malignancy. No response occurs when there is little $(<50 \%)$ or no change in the macroscopic extent of the tumour and the histology remains unaffected. 
It is important to note that $\mathrm{CR}$ and $\mathrm{PR}$ are not precise measurements but are nevertheless a useful concept both in terms of monitoring of treatment and also in relation to decision-making for further management of the patient. It is also necessary to point out that response to treatment, be it $\mathrm{CR}$ or PR, becomes meaningful when it is further quantified by duration of response and related symptomatic relief.

\section{Patient satisfaction}

The level of patient satisfaction reflects the overall quality of care as well as subjective evaluation of the treatment; it is therefore important that these should be recorded.

\section{Clinical effects and survival}

\section{Patients with advanced stage disease}

In patients with advanced disease and significant endoluminal bronchial obstruction, PDT is capable of relieving the obstruction and the related symptoms. Parallel with relief of obstruction, there is an improvement in pulmonary function and radiological clearance [87] (fig. 18). Pathologically, there is a PR in all and CR in some, irrespective of the histology [8587]. Generally, survival is related to the stage of the disease. In addition, two subsets of patients have been shown to have survival benefit. First, those with a good performance status $(<2$ WHO scale or $>50$ Karnofsky index) and, secondly, patients without extrathoracic metastases [87, 96]; histology per se does not appear to influence survival. Whilst an overall majority of cases referred for and submitted to bronchoscopic PDT have NSCLC, patients with small cell cancer also benefit from the procedure provided that there is endoluminal tumour and the aforementioned criteria are fulfilled. In some such cases, bronchoscopic PDT has been carried out concomitant to chemotherapy $[81,87,95]$ or following chemo-/radiotherapy. In fact, many patients with advanced stage type I NSCLC are referred for PDT due to recurrence of tumour after chemo-/ radiotherapy. In one series of 100 patients with advanced, inoperable cancer [87], 85\% had chemo-/radiotherapy prior to referral for PDT. It is interesting that in some cases amongst these, the endobronchial component of the tumour was found to have been nonresponsive to chemo-/radiotherapy and

\section{TABLE 4 Therapeutic endoscopy indications in lung cancers}

\begin{tabular}{|c|c|c|c|c|c|c|}
\hline Indications & $\begin{array}{l}\text { Laser-assisted } \\
\text { resection }\end{array}$ & $\begin{array}{l}\text { High-frequency } \\
\text { electrocautery }\end{array}$ & PDT & Cryotherapy & Silicone stents & Brachytherapy \\
\hline $\begin{array}{l}\text { Tracheal or bronchial } \\
\text { tumour without acute } \\
\text { dyspnoea }\end{array}$ & ++1+ & ++++ & + & +++ & NO & +++ \\
\hline Infiltrative tumour & NO & ++ & +r+t & ++r+ & NO & ++++ \\
\hline Early stages & + & H+ & +r+ & +H+ & NO & +r+t \\
\hline Coagulation & +++ immediate & +++ immediate & +/++ delayed & ++++ delayed & possible & ++++ delayed \\
\hline External compression & NO & NO & NO & NO & ++++ & + \\
\hline
\end{tabular}

PDT: photodynamic therapy; NO: not indication; +: slightly positive; ++: strongly positive; +++: very strongly positive; ++++: extremely strongly positive.

TABLE 5 Results in lung cancers

\begin{tabular}{|c|c|c|c|c|c|c|}
\hline Results & $\begin{array}{l}\text { Laser-assisted } \\
\text { resection }\end{array}$ & $\begin{array}{l}\text { High-frequency } \\
\text { electrocautery }\end{array}$ & PDT & Cryotherapy & Silicone stents & Brachytherapy \\
\hline Haemoptysis control & 60 & 90 & $50-60^{\#}$ & $65-86$ & Possible & 80 \\
\hline $\begin{array}{l}\text { Symptom } \\
\text { improvement }\end{array}$ & $80-90$ & $50-60$ & 70 & 66 & 90 & 85 \\
\hline PFT improvement & 85 & 73 & $18-25^{\circ}$ & 50 & 71 & 80 \\
\hline Ability to repeat & Yes & Yes & Yes & Yes & Yes & $\mathrm{Yes}^{+}$ \\
\hline Curative effects & Yes (selected cases) & Yes $(80)$ & Yes (77-85) & Yes (81) & No & Yes (84) \\
\hline
\end{tabular}

Data are presented as \%, unless otherwise indicated. PDT: photodynamic therapy; PFT: pulmonary functional tests; ND: not done. ${ }^{*}$ : only when caused by submucosal vessels; ${ }^{\bullet}$ : in bronchial obstructive cases; ${ }^{+}$: in selected cases. 
endoluminal volume remained unaltered at post-therapy bronchoscopic examination. These observations show that resistance or lack of response to chemo-/radiotherapy does not imply lack of response to PDT. They also suggest that there is no incompatibility between PDT and chemo-/radiotherapy.

\section{Patients with early stage cancer}

Many patients with early lung cancer are asymptomatic and assessment of results in this subgroup is based on pathological response and survival. In general, $C R$ is achieved in all patients, albeit for a variable length of time. It should be noted that monitoring response to treatment in early stage bronchial cancer may prove difficult without the added assistance of fluorescence bronchoscopy. This is because localisation of the treated area for sampling may prove impossible with the use of white light bronchoscopy alone. Also, without fluorescence endoscopy, newly developed early cancer could either escape detection or be assumed to be at the previously treated area. Bronchoscopic PDT can achieve long survival amounting to cure of disease in patients, with early superficial lung cancer confined to the bronchial wall. The Tokyo Medical University has the largest experience of bronchoscopic PDT in early lung cancer and has shown a nearly $60 \%$ overall 5 -yr survival and $>90 \%$ cancer-specific survival in such patients [81, 97]. The present author's group at the YLC, with a smaller series, has also shown comparable results [96]. A review of 12 articles from world literature involving 650 patients undergoing bronchoscopic PDT for early cancer [85] shows that long survival of $>5 \mathrm{yrs}$ is achieved in $>50 \%$ of cases. The inconsistency of long-term response is, according to the author's belief, related to difficulty in defining the "earliness" of the tumour.

\section{Conclusions}

There is sufficient evidence to state that bronchoscopic PDT is a safe and effective method of therapy for central type (type I) lung cancer using sensitisers that are currently tried and licensed; Photofrin ${ }^{\circledR}$ (Porfimer Sodium) is the commonest in use. Photosensitivity skin reaction (skin burn) should not be a prohibitive factor; its incidence and severity can be reduced to a minimal proportion with effective counselling.

The pre-requisite for bronchoscopic PDT is identifiable cancer in the bronchial tree and confirmation of its malignancy by cyto/histology.

Bronchoscopic PDT is indicated in two groups of patients with central type (type I) cancer. 1) Patients with advanced disease or with existing and/or impending symptoms. The aim in this group is palliation of symptoms and PDT is shown to achieve this goal. Patients with no extrathoracic metastases and those with good performance status will have survival benefit. Such cases should be offered other bronchoscopic treatment such as Nd-YAG laser. 2) Patients with early stage cancer. In these, the aim is curative intent and PDT is shown to provide long survival and is potentially capable of disease cure.

\section{Final conclusion}

As underlined in this article, cryotherapy, brachytherapy and photodynamic therapy represent three different techniques to treat endoluminal tumours. None of them are perfect and each has specific indications. Unfortunately, no comparative studies have been published. Tables 4 and 5 attempt to summarise the indications and results of each method compared with others. In many situations, these methods should be complementary, particularly cryotherapy and brachytherapy, and photodynamic therapy and brachytherapy. The combination of these endoscopic methods with chemotherapy should be widely tested to promote the adjuvant role of the endoscopic methods in the treatment of lung cancers.

\section{ACKNOWLEDGEMENTS}

The authors would like to thank G. Collier (Cardiff, UK) for help with the English language. K Moghissi would like to thank K. Dixon for her editorial work on the manuscript and E. Binnington and J. Melvin for secretarial work.

\section{REFERENCES}

1 Arnott J. On the Treatment of Cancer Through the Regulated Application of an Anaesthetic Temperature. London, J. Churchill, 1851; p. 32.

2 Rowbotham G, Haigh AC, Leslie WG. Cooling canula for use in treatment of cerebral neoplasms. Lancet 1959; 1: 12.

3 Gage AA. : Cryotherapy for cancer. In: Rand R, Rinfret A, Von Leden H, eds. Cryosurgery. Springfield, Charles C. Thomas, 1968; pp. 376-387.

4 Cooper IS, Lee A. Cryothalamectomy-hypothermic coagulation: a technical advance in basal ganglia surgery. Preliminary report. J Am Geriatr 1962; 9: 714.

5 Sanderson DR, Neel HB, Payne WS, Woolner LB. Cryotherapy of bronchogenic carcinoma. Report of a case. Mayo Clin Proc 1975; 50: 435-437.

6 Sanderson DR, Neel HB, Fontana RS. Bronchoscopic cryotherapy. Ann Otol 1981; 90: 354-358.

7 Rodgers BM, Moazam F, Talbert JL. Endotracheal cryotherapy in the treatment of refractory airways strictures. Ann Thorac Surg 1983; 35: 52-57.

8 Carpenter RG, Neel HB, Sanderson DR. Cryotherapy of bronchopulmonary structures. Chest 1977; 72: 279-284.

9 Homasson JP, Renault P, Angebaut M, Bonniot JP, Bell NJ. Bronchoscopic cryotherapy for airway strictures caused by tumors. Chest 1986; 90: 159-164.

10 Vergnon JM, Guichenez Ph, Fournel P, Emonot A. Efficiency of cryotherapy in bronchial tumors. Am Rev Respir Dis 1990; 141: A402.

11 Eichler B, Savy FP, Melloni B, Germouty JD. Désobstruction tumorale par cryothérapie souple. [Tumoral tracheobronchial deobstruction by cryotherapy using a flexible catheter]. Presse Med 1988; 17: 2138-2139.

12 Maiwand MO, Homasson JP. Cryotherapy for tracheobronchial disorders. Clinics in chest medicine 1995; 16: 427-443.

13 Homasson JP, Thiery JP, Angebault M, Ovtracht L, Maiwand A. The operation and efficacy of cryosurgical, nitrous oxide-driven cryoprobe. I. Cryoprobe physical characteristics: their effects on cell cryodestruction. Cryobiology 1994; 31: 290-304.

14 Walsh D, Maiwand O, Nath A, Lockwood P, Lloyd M, Saab M. Bronchoscopic cryotherapy for advanced bronchial carcinoma. Thorax 1990; 45: 509-513.

15 Homasson JP, Pecking A, Roden S, Angebaut M, Bonniot JP. Tumor fixation of bleomycin labeled with 57 
cobalt before and after cryotherapy of bronchial carcinoma. Cryobiology 1992; 29: 543-548.

16 Vergnon JM, Schmitt T, Alamartine E, Barthelemy JC, Fournel P, Emonot A. Initial combined cryotherapy and irradiation for unresectable non-small cell lung cancer. Chest 1992; 102: 1436-1440.

17 Mathur P, Wolf KM, Busk MF, et al. Fiberoptic bronchoscopic cryotherapy in the management of tracheobronchial obstruction. Chest 1996; 110: 718-723.

18 Forest V, Peoc'h M, Campos L, Guyotat D, Vergnon JM. Effects of cryotherapy or chemotherapy on apoptosis in a non-small-cell lung cancer xenografted into SCID mice. Cryobiology 2005; 50: 29-37.

19 Vergnon J-M. How I do it: bronchoscopic cryotherapy. J Bronchol 1995; 2: 323-327.

20 Mazur P. The freezing of biological systems. Science 1970; 168: 939-949.

21 Neel HG, Farrell KH, Payne WS. Cryosurgery of respiratory structures 1-cryonecrosis of trachea and bronchus. Laryngoscope 1973; 83: 1062-1071.

22 Vergnon JM. Cryothérapie endobronchique: techniques et indications. [Endobronchial cryotherapy: techniques and indications]. Rev Mal Respir 1999; 16: 619-623.

23 Homasson JP. Bronchoscopic cryotherapy. Journal Bronchol 1995; 2: 145-153.

24 Schumann C, Mattfeldt T, Hetzel M, Hetzel J, Lepper PM. Improving the diagnostic yield of endobronchial biopsies by flexible cryoprobe in lung cancer-comparison of forceps and cryoprobe technique. Eur Respir J 2004; 24: Suppl. 48, S491.

25 Deygas N, Froudarakis M, Ozenne G, Vandevenne A, Fournel P, Vergnon JM. Cryotherapy in early superficial bronchogenic carcinoma. Chest 2001; 120: 26-31.

26 Ikekawa S, Ishihara K, Tanaka S, Ikeda S. Basic studies of cryochemotherapy in a murine tumor system. Cryobiology 1985; 22: 477-483.

27 Yankauer S. Two cases of lung tumor treated bronchoscopically. N Y Med J 1922; 741.

28 Henschke UK. Interstitial implantation in the treatment of primary bronchogenic carcinoma. Am J Roentgenol 1958; 79: 81-89.

29 Henschke UK, Hilaris BS, Mahan GD. Remote afterloading with intracavitary applicators. Radiology 1964; 83: 344.

30 Hilaris BS, Nori D, Anderson LL. An Atlas of Brachytherapy: Clinical Applications in Cancer of the Lung. New York, Macmillan, 1988; pp. 184-202.

31 Bergner A, Stief J, Holdenrieder S, et al. Effects of singledose irradiation on bronchial epithelium: a comparison of BEAS 2B cell monolayers, human organ cultures, and Goettinger minipigs. Rad Res 2003; 160: 647-654.

32 Kotsianos D, Bach D, Gamarra F, et al. High-dose rate brachytherapy: dose escalation in three-dimensional miniorgans of the human bronchial wall. Int J Radiation Oncology Biol Phys 2000; 46: 1267-1273.

33 Fischer R, Huber RM. Interventional bronchoscopy: Endoluminal brachytherapy in central lung cancer. Prog Respir Res 2000; 30: 146-158.

34 Nag S, Kelly JF, Horton JL, et al. Brachytherapy for carcinoma of the lung. Oncology 2001; 15: 371.

35 Speiser B, Spratling L. Intermediate dose rate remote afterloading brachytherapy for intraluminal control of bronchogenic carcinoma. Int J Radiat Oncol Biol Phys 1990; 18: 1443-1448.

36 Speiser BL. Advantages of high dose rate remote afterloading systems: physics or biology. Int J Radiat Oncol Biol Phys 1991; 20: 1133-1135.

37 Huber RM, Fischer R, Hautmann $\mathrm{H}$, et al. Palliative endobronchial brachytherapy for central lung tumors: a prospective, randomized comparison of two fractionation schedules. Chest 1995; 107: 463-470.

38 Miller JI Jr, Phillips TW. Neodymium:YAG laser and brachytherapy in the management of inoperable bronchogenic carcinoma. Am Thorac Surg 1990; 50: 190-195.

39 Spratling L, Speiser BL. Endoscopic brachytherapy. Chest Surg Clin N Am 1996; 6: 293-304.

40 Nag S, Abitbol AA, Anderson LL, et al. Consensus guidelines for high dose rate remote brachytherapy in cervical, endometrial, and endobronchial tumors. Clinical Research Committee, American Endocurietherapy Society. Int J Radiat Oncol Biol Phys 1993; 27: 1241-1244.

41 Saito M, Yokoyama A, Kurita Y, Uematsu T, Miyao H, Fujimori K. Treatment of roentgenographically occult endobronchial carcinoma with external beam radiotherapy and intraluminal low dose rate brachytherapy. Int J Radiat Oncol Biol Phys 1996; 34: 1029-1035.

42 Huber RM, Fischer R, Hautmann H, Pollinger B, Häußinger $K$, Wendt T. Does additional brachytherapy improve the effect of external irradiation? A prospective, randomized study in central lung tumors. Int J Radiat Oncol Biol Phys 1997; 38: 533-540.

43 Hemandez P, Gursahaney A, Roman T, et al. High dose rate brachytherapy for the local control of endobronchial carcinoma following external irradiation. Thorax 1996; 51: 354-358.

44 Yokomise H, Nishimura Y, Fukuse T, et al. Long-term remission after brachytherapy with external irradiation for locally advanced lung cancer. Respiration 1998; 65: 489-491.

45 Aygun C, Weiner S, Scariato A, Spearman D, Stark L. Treatment of non-small cell lung cancer with external beam radiotherapy and high dose rate brachytherapy. Int $J$ Radiat Oncol Biol Phys 1992; 23: 127-132.

46 Bastin KT, Mehta MP, Kinsella TJ. Thoracic volume radiation sparing following endobronchial brachytherapy: a quantitative analysis. Int J Radiat Oncol Biol Phys 1993; 25: 703-707.

47 Marsiglia H, Baldegrou P, Lartigau E, et al. High dose rate brachytherapy as sole modality for early-stage endobronchial carcinoma. Int J Radiat Oncol Biol Phys 2000; 47: 665-672.

48 Sutedja G, Baris G, van Zandwijk N, Postmus PE. Highdose rate brachytherapy has a curative potential in patients with intraluminal squamous cell lung cancer. Respiration 1994; 61: 167-168.

49 Tredaniel J, Hennequin C, Zaleman G, et al. Prolonged survival after high dose rate endobronchial radiation for malignant airway obstruction. Chest 1994; 105: 767-772.

50 Perol M, Caliandro R, Pommier P, et al. Curative irradiation of limited endobronchial carcinomas with high-dose rate brachytherapy. Results of a pilot study. Chest 1997; 111: 1417.

51 Vonk-Norordegraaf A, Postmus PE, Sutedja TG. Bronchoscopic treatment of patients with intraluminal 
microinvasive radiographically occult lung cancer not eligible for surgical resection: a follow-up study. Lung cancer 2003; 39: 49-53.

52 Kramer MR, Katz A, Yarmolovsky A, Schifter D, Fenig E. Successful use of high dose rate brachytherapy for nonmalignant bronchial obstruction. Thorax 2001; 56: 415-416.

53 Kennedy AS, Sonett JR, Orens JB, et al. High dose brachytherapy to prevent recurrent benign hyperplasia in lung transplant bronchi: theoretical and clinical considerations. J Heart Lung Transplant 2000; 19: 155-159.

54 Schray MF, Mcdougall JC, Martinez A, et al. Management of malignant airway compromise with laser and low dose rate brachytherapy. The Mayo Clinic experience. Chest 1988; 93: 264.

55 Taulelle M, Chauvet B, Vincent $\mathrm{P}$, et al. High dose rate endobronchial brachytherapy: results and complications in 189 patients. Eur Respir J 1998; 11: 162.

56 Kelly JF, Delclos ME, Morice RC, Huaringa A, Allen PK, Komaki R. High-dose-rate endobronchial brachytherapy effectively palliates symptoms due to airway tumors: the 10-years M.D. Anderson Cancer center experience. Int J Radiat Oncol Biol Phys 2000; 48: 697-702.

57 Escobar-Sacristán JA, Granda-Orive JI, Gutiérrez Jiménez T, Delgado JM, Rodero Banos A, Saez Valls R. Endobronchial brachytherapy in the treatment of malignant lung tumours. Eur Respir J 2004; 24: 348-352.

58 Goldman JM, Bulman AS, Rathemell AJ, Carey BM, Muers MF, Joslin CA. Physiological effect of endobronchial radiotherapy in patients with major airway occlusion by carcinoma. Thorax 1993; 48: 110-114.

59 Miller KL, Shafman TD, Anscher MS, et al. Bronchial stenosis: an underreported complication of high dose external beam radiotherapy for lung cancer? Int J Radiation Oncology Biol Phys 2005; 61: 64-69.

60 Speiser B, Spratling I. Remote afterloading brachytherapy for the local control of endobronchial carcinoma. Int $J$ Radiat Oncol Biol Phys 1993; 25: 579-589.

61 Cox JD, Yesner R, Mietlowski W, Petrovich Z. Influence of cell type on failure pattern after irradiation for locally advanced carcinoma of the lung. Cancer 1979; 44: 94-98.

62 Miller RR, McGregor DH. Hemorrhage from carcinoma of the lung. Cancer 1980; 46: 200-205.

63 Hara R, Itami J, Aruga T, et al. Risk factors for massive hemoptysis after endobronchial brachytherapy in patients with tracheobronchial malignancies. Cancer 2001; 92: 2623-2627.

64 Langendijk JA, Tjwa MK, de Jong JM, et al. Massive haemoptysis after radiotherapy in inoperable non-small cell lung carcinoma: is endobronchial radiotherapy really a risk factor? Radiother Oncol 1998; 49: 175-183.

65 Chella A, Ambrogi MC, Ribechini A, et al. Combined NdYAG-laser/HDR brachytherapy versus Nd-YAG-laser only in malignant central airway involvement: a prospective randomized study. Lung Cancer 2000; 27: 169-175.

66 Mathur PN, Edell E, Sutedja T, Vergnon J-M. Treatment of early stage non-small cell lung cancer. Chest 2003; 123: 176S-180S.

67 Freitag L, Ernst A, Thomas M, Prenzel R, Wahlers B, Macha H-N. Sequential photodynamic therapy (PDT) and high dose brachytherapy for endobronchial tumour control in patients with limited bronchogenic carcinoma. Thorax 2004; 59: 790-793.

68 Lee JS, Komaki R, Morice RC, et al. A pilot clinical laboratory trial of paclitaxel and endobronchial brachytherapy in patients with non-small cell lung cancer. Semin Radiat Oncol 1999; 9: Suppl. 1, 121-129.

69 Allison R, Downie G, Cuenca R, Hu XH, Childs C, Sibata $\mathrm{CH}$. Photosensitisers in clinical PDT. Photodiagnosis Photodynamic Therapy 2004; 1: 27-42.

70 Finsen NF. Phototherapy. London, Arnold, 1901.

71 Raab O. The effect of fluorescent substances oninfusoria. $Z$ Biol 1900; 39: 524-546.

72 von Tappeiner H, Jodlbauer A. The sensitising action of fluorescent substance. An overall account of investigations on Photodynamic phenomena. Leipizig, FCW Vogel, 1907.

73 Jodlbauer A, von Tappeiner $\mathrm{H}$. On the participation of oxygen in the photodynamic effect of fluorescent substances. Munch Med Wochenschr 1904; 52: 1139-1141.

74 Jesionek A, von Tappeiner H. On the treatment of skin cancers with fluorescent substances. Arch Klin Med 1905; 82: 223-227.

75 Lipson RL, Gray MJ, Blades EJ. Haematoporphryin derivative for detection and management of cancer. Abstr Proc 9th Int Cancer Congress Tokyo 1966; Section, II-01-a: 50696.

76 Dougherty TJ, Grindey GB, Fiel R, Wishaupt KR, Boyle DG. Photoradiation therapy: II. Cure of animal tumours with haematoporphyrin and light. J Natl Cancer Inst 1975; 55: 115-119.

77 Kelly JF, Snell ME. Haematoporphyrin derivative: a possible aid in the diagnosis and therapy of carcinoma of the bladder. J Urol 1976; 155: 150-151.

78 Dougherty TJ, Kaufman JE, Goldfarb A, Weihaupt KR, Boyle DG, Mitleman A. Photoradiation for the treatment of malignant tumours. Cancer Res 1978; 38: 2628-2635.

79 Dougherty TJ, Lawrence G, Kaufman JE, Boyle D, Weishaupt KR, Goldfarb A. Photoradiation in the treatment of recurrent breast carcinoma. J Natl Cancer Institute 1979; 68: 231-237.

80 Hyata $Y$, Kato H, Kanoka C, et al. Fiberoptic bronchoscopic laser photo-radiation for tumour localisation in lung cancer. Chest 1982; 82: 10-14.

81 Kato H. Photodynamic therapy for lung cancer. A review of 19 years experience. J Photochem Photobiol B Biol 1998; 42: 96-99.

82 Hyata Y, Kato H, Konaka C, Ono J, Takizawa W. Haematoporphyrin derivative and laser photoradiation in the treatment of lung cancer. Chest 1982; 81: 269-277.

83 Balchum OJ, Doiron ER, Huth GC. PDT for endobronchial lung cancer employing the photodynamic action of the haematoporphyrin derivative. Laser Surg Med 1984; 14: 13-30.

84 Edell ES, Cortese DA. Bronchoscopic photodynamic therapy with haematoporphyrin for treatment of localised bronchogenic carcinoma: a 5 year experience. Mayo Clinic Proc 1987; 14: 62-68.

85 Moghissi K, Dixon K. Is bronchoscopic photodynamic therapy a therapeutic option in lung cancer? Eur Respir J 2003; 22: 535-541.

86 Mccaughan JS Jr, Williams TF. Photodynamic therapy for endobronchial malignant disease: a prospective 14 year study. J Thorac Cardiovasc Surg 1997; 114: 940-947. 
87 Moghissi K, Dixon K, Stringer MR, Freeman T, Thorpe A, Brown S. The place of bronchoscopic photodynamic therapy in advanced unresectable lung cancer: experience with 100 cases. Eur J Cardiothorac Surg 1999; 15: 1-6.

88 Grosjean P, Savary JF, Mizeret J, et al. Photodynamic therapy for cancer of the upper aerodigestive tract using tetra(m-hydroxyphenyl)chlorin. J Clin Laser Med Surg 1996; 14: 281-287.

89 Mang TS. Lasers and light sources for PDT: past, present and future. Photodiagnosis Photodynamic Therapy 2004; 1: 43-48.

90 Uicc TNM. Classification of Malignant Tumours. 5th Edn. Chichester, Wiley-Liss Publications, 1997.

91 Lam S, Kennedy T, Ungar M, et al. Localisation of bronchial neoplastic lesions by fluorescence bronchoscopy. Chest 1998; 113: 696-702.

92 Lam S, Zeng H, McWilliams A. Optical spectroscopy and imaging for early lung cancer detection: a review article. Photodiagnosis Photodynamic Therapy 2004; 1: 111-122.
93 Herth F, Becker H. Endobronchial ultrasound of the airways and mediastinum. Monaldi Arch Chest Dis 2000; 55: 36-44.

94 Herth F, Becker HD, Locicero J, Ernst A. Endobronchial ultrasound in therapeutic bronchoscopy. Eur Respir J 2002; 20: $118-121$.

95 Takahashi H, Sagawa M, Sato M, et al. A prospective evaluation of transbronchial ultrasonography for assessment of depth of invasion in early bronchogenic squamous cell carcinoma. Lung Cancer 2003; 42: 43-49.

96 Moghissi K, Dixon K, Thorpe JAC, Oxtoby C, Stringer MR. Photodynamic Therapy (PDT) for lung cancer: The Yorkshire Laser Centre experience. Photodiagnosis and Photodynamic Therapy 2004; (In press).

97 Kato H, Harada M, Ichinose S, Usuda J, Tschuchida T, Okunaka T. Photodynamic therapy (PDT) of lung cancer: experience of the Tokyo Medical University. Photodiagnosis Photodynamic Therapy 2004; 1: 49-55. 